\title{
Performance Characteristics of A Micro Wind Turbine Integrated on A Noise Barrier
}

\author{
Nikolaos Chrysochoidis-Antsos ${ }^{1, *}$, Gerard J.W. van Bussel ${ }^{2}$, Jan Bozelie ${ }^{3}$, Sander M. Mertens 4 \\ and Ad J.M. van Wijk ${ }^{1}$ \\ 1 Department of Process \& Energy (P\&E), Delft University of Technology, 2628 CB Delft, The Netherlands; \\ A.J.M.vanWijk@tudelft.nl \\ 2 Department of Aerodynamics Wind Energy Flight Performance \& Propulsion (AWEP), Delft University of \\ Technology, 2629 HS Delft, The Netherlands; G.J.W.vanBussel@tudelft.nl \\ 3 Qirion Alliander, 6921 RL Duiven, The Netherlands; Jan.Bozelie@qirion.nl \\ 4 De Haagse Hogeschool, The Hague University, 2628 AL Delft, The Netherlands; S.Mertens@hhs.nl \\ * Correspondence: n.chrysochoidis-antsos@tudelft.nl; Tel.: +31-6-207-49-804
}

Citation: Chrysochoidis-Antsos, N.; van Bussel, G.J.W.; Bozelie, J.;

Mertens, S.M.; van Wijk, A.J.M. Performance Characteristics of A Micro Wind Turbine Integrated on A Noise Barrier. Energies 2021, 14, 1288. https://doi.org/10.3390/en14051288

Academic Editor: David Wood

Received: 26 January 2021

Accepted: 19 February 2021

Published: 26 February 2021

Publisher's Note: MDPI stays neutral with regard to jurisdictional claims in published maps and institutional affiliations.

Copyright: (c) 2021 by the authors. Licensee MDPI, Basel, Switzerland. This article is an open access article distributed under the terms and conditions of the Creative Commons Attribution (CC BY) license (https:/ / creativecommons.org/licenses/by/ $4.0 /)$.

\begin{abstract}
Micro wind turbines can be structurally integrated on top of the solid base of noise barriers near highways. A number of performance factors were assessed with holistic experiments in wind tunnel and in the field. The wind turbines underperformed when exposed in yawed flow conditions. The theoretical $\cos \theta$ theories for yaw misalignment did not always predict power correctly. Inverter losses turned out to be crucial especially in standby mode. Combination of standby losses with yawed flow losses and low wind speed regime may even result in a net power consuming turbine. The micro wind turbine control system for maintaining optimal power production underperformed in the field when comparing tip speed ratios and performance coefficients with the values recorded in the wind tunnel. The turbine was idling between $20 \%-30 \%$ of time as it was assessed for sites with annual average wind speeds of three to five meters per second without any power production. Finally, the field test analysis showed that inadequate yaw response could potentially lead to $18 \%$ of the losses, the inverter related losses to $8 \%$, and control related losses to $33 \%$. The totalized loss led to a $48 \%$ efficiency drop when compared with the ideal power production measured before the inverter. Micro wind turbine's performance has room for optimization for application in turbulent wind conditions on top of noise barriers.
\end{abstract}

Keywords: micro wind turbines; performance; experiment; field test

\section{Introduction}

Micro wind turbines have a potential to be utilized for energy production in the urban environment. In order to reduce electricity production costs they can be installed on buildings or on infrastructure. This has already been demonstrated at an affordable cost for photovoltaics in the urban environment. The challenge is also indicated in a cost comparison of free standing micro wind turbines ranging from 6700 to $10900 € / \mathrm{kW}$ (2017 equivalent from US dollars) [1], while photovoltaic (PV) systems range from 2500-6700 €/kW (2017 equivalent from US dollars) [2]. Therefore, research is needed to find ways to reduce costs for micro wind turbines and optimize the performance characteristics, thus lowering electricity production costs.

For micro wind turbines, there are numerous claims, showing a wide range of energy efficiencies and a wide range of costs, which are caused by an unregulated market without proper standardization. Also, their operating performance differs largely per wind turbine system and site of installation, hence more research is needed to identify all possible issues. The poor performance of numerous systems is shown in [3] where capacity factors were found extremely low up to an average of 0.085 when taking into account electrical standby losses and 0.0415 when not. The ranges of the capacity factors of the various examined 
sites in England were between 0.001-0.20. This means that it is a difficult task for installers to select a proper micro wind turbine system for a particular site. This paper addresses some of the above issues as they have been found through experiments both in a wind tunnel and from a field experiment on a noise barrier.

The micro wind turbine system that is examined in this article is structurally integrated with noise barriers as seen in Figure 1. Noise barriers are part of many highway infrastructures passing through populated areas and reduce the noise produced by the passing vehicles. If micro wind turbines are structurally integrated with noise barriers, then a part of the structural costs of the micro wind turbines is reduced due to the use of its heavy support foundations that these barriers can provide to locate these turbines (multiple infrastructure use). The tower costs for micro wind turbines can vary from $13 \%-31 \%$ of the total investment cost [4] and if replaced instead by a simple flange as in Figure 1 in blue, the electricity cost could be reduced. A similar integration has been demonstrated in [5] for roof- and wall-mounted micro wind turbine applications on buildings.

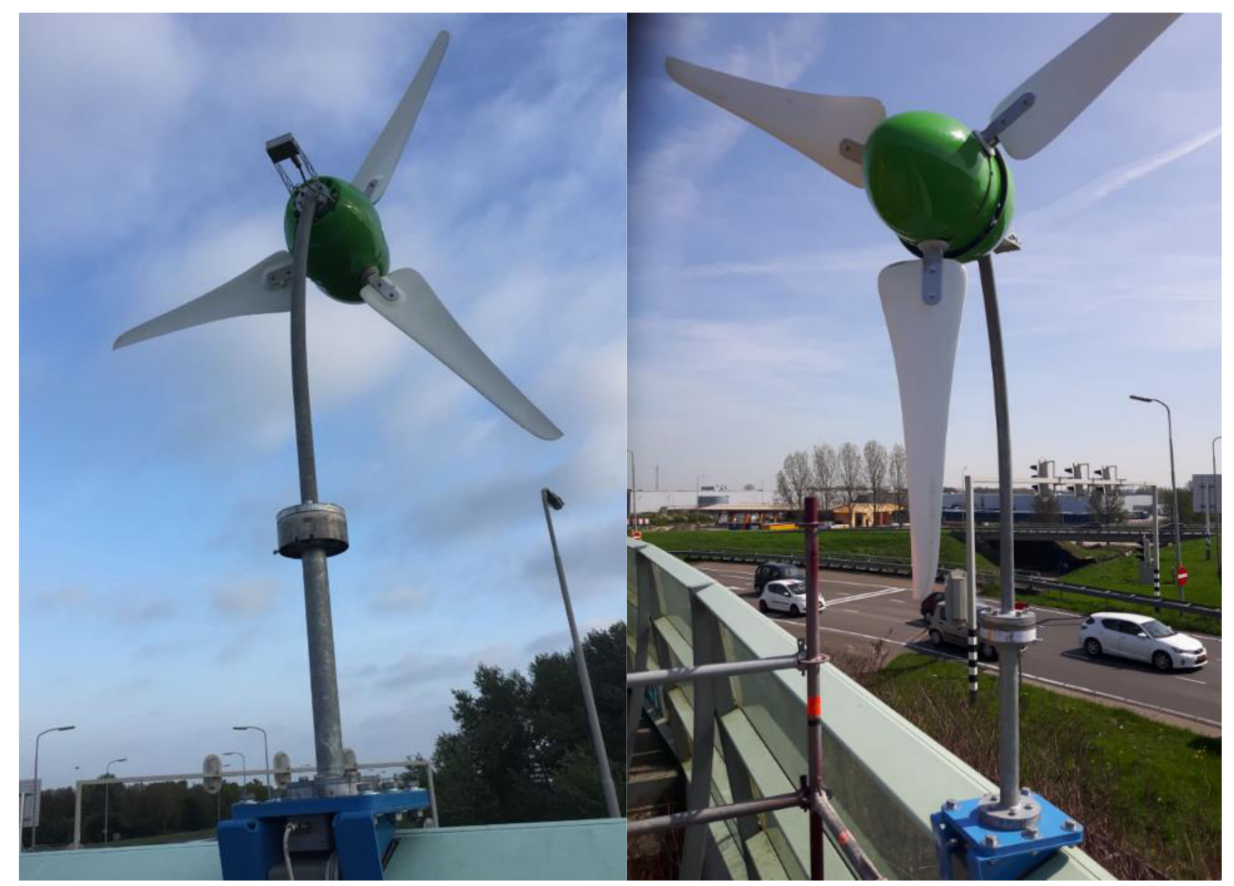

Figure 1. Micro wind turbine integrated on top of the noise barrier.

In this article, a number of performance characteristics are investigated and a state-ofthe-art literature review is presented below. The intention is to aggregate the most relevant aspects that determine the performance of a micro wind turbine in an urban environment. The relevant characteristics are summarized as:

(1) Flow misalignment in open air experiments

(2) Electrical power conversion losses under dynamic external conditions

(3) Starting behavior of micro wind turbines in a varying wind speed environment

(4) Optimal power control of micro wind turbines in urban wind conditions

The first performance characteristic of this article refers to the misalignment of the flow with respect to the rotor. Wind flows passing through the rotor of micro wind turbines installed in urban environments, such as on noise barriers are not always perpendicular with the rotor. This misalignment effect can be observed under two different operational conditions. The first condition is when the wind flows are affected by urban obstacles such as a noise barrier, thus resulting in a skewed flow towards the rotor. In the second condition is the misalignment of the rotor with the flow due to the inadequate yaw response of the micro wind turbine's hub with the rapidly occurring wind variations at low heights. 
The first operational condition has been examined in [6] where it was shown that flow on top of noise barriers is constantly misaligned with a range from +5 to +25 degrees for all wind flow directions towards the barrier. This constant flow misalignment was shown to lower the performance. The performance assessment was theoretically modelled with $\cos ^{3} \theta$ law that predicted power under skewed flow. The intention of the current article is twofold. First to observe the validity of those theories with wind tunnel experiments presented in the Section 3.1.1 and second to apply the theory and wind tunnel results for observations from the field experiment.

Regarding the different theories for prediction of power in misaligned flows, much literature is presented. For example, in [7], a rotor power measurement under yawed conditions was performed in a wind tunnel. It was found that there were anomalies from model predictions regarding rotor power responses to yaw error variations in experimental data. The conclusion was that higher accuracy prediction of wind turbine power performance under yaw conditions required a more complete understanding of rotor and blade aerodynamics. In [8], large eddy simulations were performed for yawed rotors of large wind scale turbines. The authors found that the $\cos ^{2} \theta$ and $\cos ^{3} \theta$ power decay laws respectively over and underestimate the power production in the experimental datasets for an inflow with shear. In [9] and [10], the maximum power production versus the tip speed ratio (TSR) was found to vary approximately like $\cos ^{3}(\theta)$, where $\theta$ is the yaw angle in this case. The turbine used in this experiment was rather small with a diameter of $0.15 \mathrm{~m}$ and placed at a height of $0.125 \mathrm{~m}$ from the floor of the closed-loop tunnel. The power was extracted with a small Direct Current (DC) generator. Even though the $\cos \theta$ law was applicable for this small turbine, care should be taken because the airfoils of such a small turbine operate in very viscous flow and as a consequence the behavior will be different from a larger turbine with airfoils that operate at higher Reynolds numbers. In [11], yaw misalignment was studied for the MEXICO rotor with Computational Fluid Dynamics (CFD) for three wind speeds at $30^{\circ}$ yaw angle with respect to aerodynamic performance for a $4.5 \mathrm{~m}$ diameter. In [12], wind turbine power performance was also investigated, showing drops up to $40 \%$ in the power coefficient $C_{p}$ with an increasing inclined flow (towards $40^{\circ}$ ) for a $75 \mathrm{~kW}$ system. Finally, in [13] a drop in the thrust coefficient $C_{T}$ and therefore in $C_{p}$ was observed for micro wind turbines in wind tunnel experiments for measurements of wakes from yawed flow from 0-45 degrees. In the present paper, a $\operatorname{comparison}$ of the $\cos \theta$, $\cos ^{2} \theta$ and $\cos ^{3} \theta$ laws was performed with experimental data from several wind turbine configurations and at different yaw position. These theoretical approximations are based on the momentum theory in steady yaw, the Glauert momentum theory model, and the vortex cylinder model, which seem to be applicable for large scale wind turbines [14].

Beside flow misalignment losses, which were part of the noise barrier structural integration, there were electrical losses that made the system inefficient. These were further classified in generator losses and power conversion losses. In this study, the focus lies on the power conversion losses with the point of measuring efficiency right after the generator and before the inverter. Also, the inverter efficiency was determined during the operation of the wind turbine. Nevertheless, some notable studies on efficiencies also including generator losses were referred to as well. The conversion of mechanical power to electrical within the generator for a miniature wind-turbine was observed in [15], where a micro wind turbine of $0.15 \mathrm{~m}$ diameter was tested in a wind tunnel with various DC generators. Performance of the generator was also assessed in [16] for a miniature wind turbine. These studies presented losses between $60 \%-80 \%$ for DC generators. In the present study, a PMSG generator was used for which better efficiencies were achieved up to 95\% [17]. But as said, the aim was not to study the generator losses but to focus on power conversion losses.

Power conversion related losses occurred in the conversion of the generator's Alternating Current (AC) to Direct Current (DC) for boosting up then back to fixed frequency AC for grid connection. Most commercial micro wind turbines have a Permanent Magnet Synchronous Generator (PMSG) that produces a three-phase power which is rectified to DC and then depending on the voltage level of the generator a buck-boost converter brings it to 
each AC grid country compatible frequency. The instantaneous loss was dependent on the different electronic components and configurations and could be between $20 \%-40 \%$ [18]. These losses accumulate in the total power performance and can vary greatly depending on rectifier topology [19-21]. The literature also indicated other electrical losses that should not be neglected as it might lead to considerable reduction in cumulative energy yield. These are, for example, the standby losses of the inverter connected to the turbine. Such losses are hardly ever taken into account in commercial micro wind turbine manufacturer websites and brochures. The standby losses depending on the inverter can contribute to a considerable amount of energy lost. The field trials from Energy Savings Trust 2009 report indicated that in some cases, micro wind turbine installations were found to become net-consumers of electricity due to the power consumption of the inverter taking its power ( $10 \mathrm{~W}$ continuously) from the mains supply even when the turbine is connected but is not generating [22]. Similarly, [23] indicates that most small wind turbines have system electronics that run in standby mode or monitoring mode if the turbine is not generating. Depending on how much the wind turbine operates, these are additional losses for the micro wind turbine system. Due to lack of outdoor data in the literature, this is unfortunately hard to quantify upfront.

In the present article, the above phenomena were observed through the wind tunnel experiments in which different inverters were tested. The results were used to quantify the annual energy yield and standby losses for 9 location cases in the Netherlands with accenting wind speed. Finally, the performance of the inverter, for the experiments where the micro wind turbine was integrated on noise barrier structure, is presented.

The starting and idling behavior of the micro wind turbines was another important performance aspect not to be neglected. The low wind speeds in combination with the highly turbulent wind environment at low heights will certainly influence performance and knowing the turbine's behavior at low wind speeds is important. Most micro wind turbines need a gust to overcome cogging torque and to complete the starting sequence at low wind speeds, quite often about $4 \mathrm{~m} / \mathrm{s}$ [24]. Even when starting, the wind turbine might spend much time in idling mode until the inverter is able to boost the generator voltage to an acceptable level where it can be inverted to AC. Only then sufficient voltage is built up from the controllers in order to connect to the grid. Cogging torque is important and in [25] researchers tried to minimize it. But looking at the greater picture, the effect of the idling and starting behavior can significantly influence the overall energy yield. During the experiments that will be presented in this paper, the starting behavior of micro wind turbines is observed for various yaw positions and wind regimes. After that, a quantification of the time that turbine would be in idle, stop, or operation is presented for different wind speeds.

Finally, the performance aspect of controlling a micro wind turbine is crucial for identifying the maximum power performance point. Wind turbines have an optimal operating rotational speed for each wind speed. This rotational speed gives the best aerodynamic power extraction from the given wind flow [26]. The system's controller should ideally control the power electronics in order to find the optimum rotational speed in rotations per minute(RPM) at all times for all wind speeds. If such controller is badly designed then a potential micro wind turbine project can turn into a financial disaster. There are numerous studies on control of micro and small wind turbines and on how to assess and define the performance metrics such as power coefficient $C_{p}$ and tip speed ratio (TSR or $\lambda$ ) curve for micro wind turbines.

In [27], the authors address the importance of the $C_{p}-\lambda$ curve for micro wind turbine operation and how power electronic converters are currently programmed with power and speed curves, which do not effectively optimize the power generation. For compensating the high costs and complexity of wind tunnels, authors designed an emulator to assist the development of controllers of small wind turbines. In the present study, data are analyzed and shown with respect to the $C_{p}-\lambda$ curve response of the turbine. Additionally, a qualitative presentation of the results of the controller performance in the field experiment is 
shown to address the importance of the maximum power performance controller operating in a highly turbulent environment.

All aforementioned studies mentioned here present performance characteristics. The motivation for the current study is generated by the fact that numerous individual issues are addressed regarding the performance, but an overall holistic understanding of those characteristics with respect to the overall power production performance is lacking. The novelty in this article is hence found in a holistic approach to present and discuss the results of the experiments. One set of experiments conducted in a wind tunnel and used as a comparison basis for the other set of field experiment, where the performance of micro wind turbines integrated with highway infrastructures such as noise barriers is recorded. The article does not address the fundamentals of the aerodynamic, electrical, and control performance of the systems described, but rather addresses the key aspects that result in an energy efficient system. All the performance characteristics addressed with respect to the field experiment are classified and quantified for a 22 minute dataset. However, the results can be also interpreted in a qualitative manner and inspire the research community to investigate further those aspects in a combined holistic effort.

The article is organized as follows. In Section 1, a literature review and scope are presented. In Section 2, a detailed set-up description is presented of the wind turbine systems examined as well as the methodology used. In Section 3, results are presented for each key performance characteristic. In Section 4, a discussion on the obtained results can be found. Finally, in Section 5, the conclusions are presented.

\section{Materials and Methods}

To provide a quantitative and qualitative assessment of the performance characteristics of the micro wind turbines for installation on noise barriers, the following experimental setups, methods, hardware, and equations were used. The experiments were done in a wind tunnel under controlled conditions, in order to have a properly calibrated environment where micro wind turbine performance aspects can be determined. An outdoor field experiment with a micro wind turbine installed on top of a noise barrier was also presented in order to understand the "real-world" conditions and how such outdoor conditions can affect the performance of the micro wind turbine. Numerous wind tunnel experiments inspired the methods of this article in many ways [16,28-31].

The methods and experimental conditions for both the wind tunnel tests and the field experiment are subsequently presented in the following subsections.

\subsection{Wind Tunnel Experiment}

The experiments were conducted in the Open Jet Facility (OJF) of TU Delft. This is a closed-circuit open jet wind tunnel with a jet diameter $d_{\text {nozzle }}$ of 2.85 meters. Wind speed was measured with a pitot tube placed inside the wind tunnel's nozzle and was calibrated for the distance from the exit of nozzle in which all micro wind turbines are placed as seen below in Figure 2. Even though some literature suggests that blockage corrections are necessary even for small wind turbines like in [32] and [33], this is mainly the case for experiments in closed test sections. Since the current test object is exposed to an open jet flow in significantly larger diameter, the blockage effects were considered negligible. Open jet blockage corrections were typically one order of magnitude smaller and of opposite sign compared to closed tunnel sections with similar diameter [34]. The use of open jet sections was a well-known setup for reducing blockage effects $[35,36]$. The Open Jet Facility tunnel in TU Delft was used before with success for many aerodynamic studies on blunt body loads as well for small scale wind turbine rotors like in [37]. 


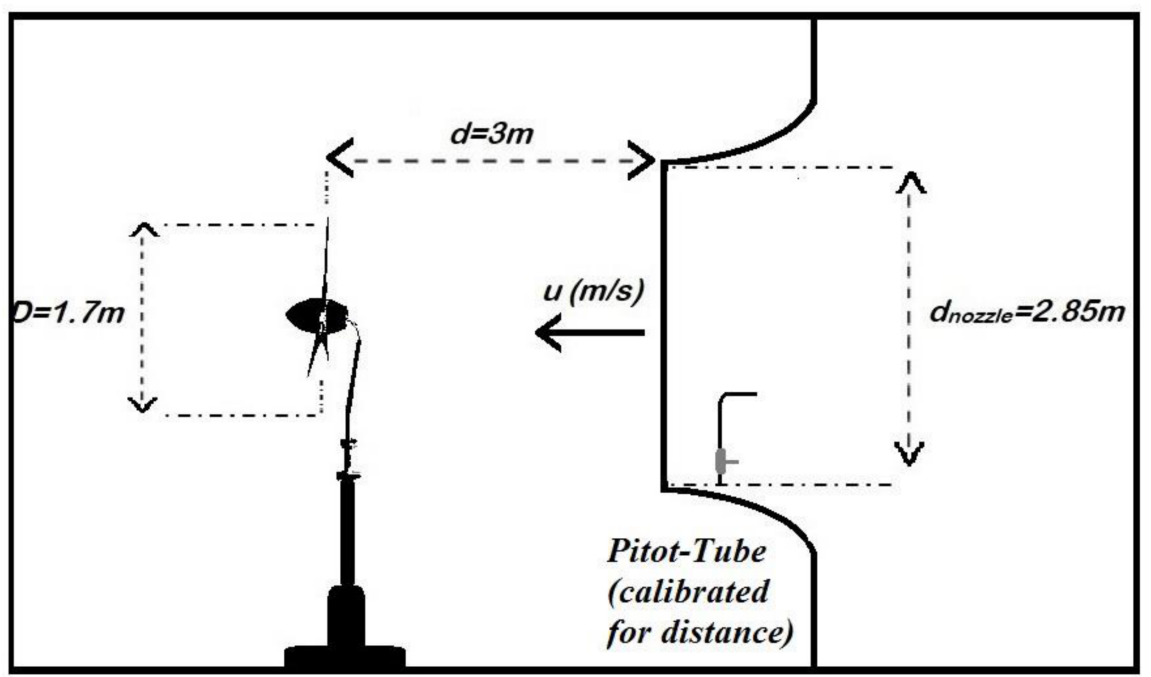

Figure 2. Diagram of installation of micro wind turbine in the Open Jet Facility (OJF) and wind speed pitot-tube.

Two commercial wind turbine hubs were used in the experiments, the DOD Electric and the WindChallenge. For the DOD Electric, 3 different rotors were used. The standard commercial 5 bladed rotor from the manufacturer, an American 5 bladed rotor, and an American 3 bladed rotor. All these rotors had a blade radius of $0.83-0.87 \mathrm{~m}$. WindChallenge was a 3 bladed downwind turbine with blade radius of $0.86 \mathrm{~m}$. All hubs had a permanent magnet synchronous generator with a rated power of 375 watts. All the turbine rotors were installed at the same distance from the wind tunnel's jet exit.

To study the losses of the inverter and the loss due to the skewed flow misalignment, the generator was directly connected to a grid-tied inverter before all energy was fed to the grid. This configuration is depicted in Figure 3. The nacelle of the wind turbine, see Figure 3, was locked at several yaw misalignment positions $\theta$ degrees with a tightening bolt. In that way, the effect of flow misalignment was calibrated and hence potential detrimental effects of the yawed and skewed flow of a micro wind turbine installed on a noise barrier can be identified.

$\mathrm{u}_{\mathrm{w}}(\mathrm{m} / \mathrm{s})$

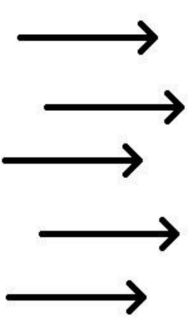

$\left.\begin{array}{l}\mathrm{V}_{\mathrm{LL}} \text { (Volts) } \\ \mathrm{IL}_{\mathrm{L}} \text { (Amps) }\end{array}\right\}$ for $\mathrm{P}_{\text {gen }}$ (Watts)

RPM(from voltage zero-crossing)

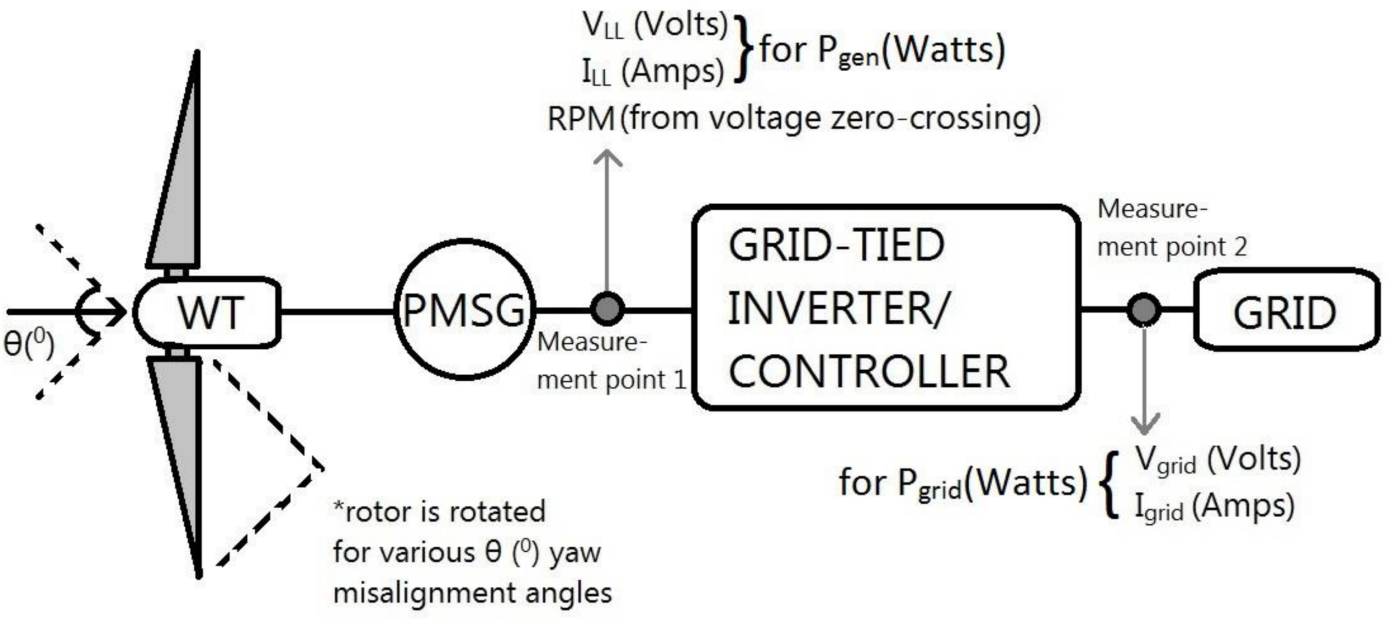

Figure 3. Schematic of configuration of skewed flow losses experiments and inverter losses for the wind turbine (WT) and its permanent magnet synchronous generator (PMSG), together with all relevant measured parameters

In order to assess the energy losses, different measurement points were defined for each configuration, as seen in Figure 3. with measurement Point 1 and 2 before and after the inverter. The measurements were recorded in a DEWETRON data acquisition computer. 
Line-to-line voltage $\mathrm{V}_{\mathrm{LL}}$ (Volts) and line-to-line current $\mathrm{I}_{\mathrm{LL}}$ (Amps) in each phase were measured with a $10 \mathrm{kHz}$ sampling frequency. Voltage was measured with DAQP-V-B and DAQP-V-HV modules and current were measured with Fluke clamp meters. For the calculations, the root-mean-square (RMS) values were considered, while the rotational speed (RPM) was estimated from the voltage zero-crossing. From those, the 3 phase power produced from the micro wind turbine was derived using the equations below. Grid voltage $V_{g}$ (volts) and grid current $I_{g}$ (Amps) measurements were also considered at the grid side and power was estimated with the equations below.

$$
\begin{gathered}
P_{\text {gen }}=\sqrt{3} \mathrm{~V}_{\mathrm{LL}} \mathrm{I}_{\mathrm{LL}} \quad \text { (watts) } \\
\mathrm{P}_{\text {grid }}=\mathrm{V}_{\mathrm{g}} \mathrm{I}_{\mathrm{g}} \text { (watts) }
\end{gathered}
$$

These power values were later processed in order to find the efficiency of the inverter, but also to compare the power values for different yaw misalignment angles $\theta\left(^{\circ}\right)$. Especially for yaw misalignment angles, a comparison of the experimentally recorded power at the measurement points with the theoretical estimation was considered. The general equation for the theoretical power $\mathrm{P}$ (watts) was estimated using $\mathrm{P}_{\text {gen }}$ (watts) at each angle $\theta^{\circ}$.

$$
\mathrm{P}\left(\theta=\theta_{\mathrm{i}}\right)=\mathrm{P}_{\text {gen }}\left(\theta=\theta^{\circ}\right) \times \cos \theta \text { (watts) }
$$

For the $C_{p}-\lambda$ study, the 3 phases of the generator were connected to a DC bridge rectifier and then to a DC controllable load unit on which a constant voltage could be set as seen in Figure 4. By setting up different voltages, the rotational speed of the rotor can be set. In that way, the performance of the micro wind turbine was assessed for different tip speed ratios TSR (see equation below). TSR is the ratio of the rotational speed $\omega(\mathrm{rad} / \mathrm{s})$ times the rotor radius $\mathrm{R}(\mathrm{m})$ divided by the incoming wind speed $\mathrm{u}_{\mathrm{w}}(\mathrm{m} / \mathrm{s})$. Further analysis of the equation to use the RPM measured from the equipment is shown in the equation.
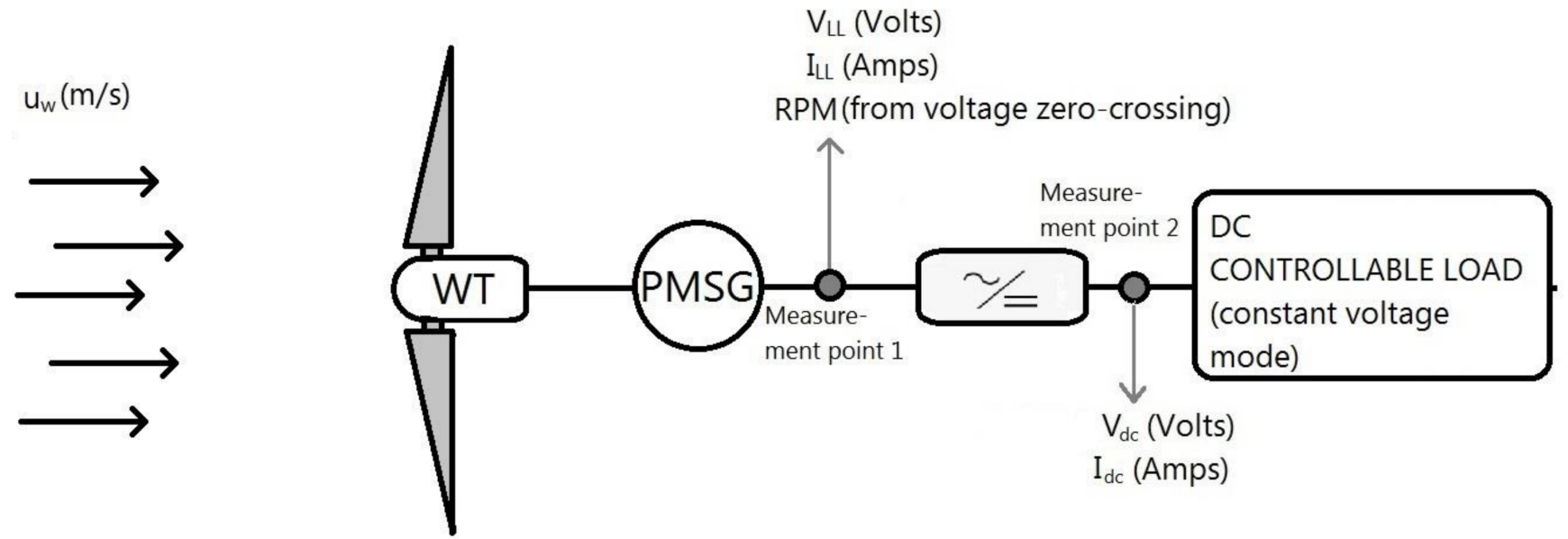

Figure 4. Configuration of DC-controllable load tests in wind tunnel.

Studying the TSR and generated power at each instance was important since this can confirm if the commercial MPPT (Maximum Power Point Tracker) inverters used were operating in the maximum performance possible. This configuration is visualized in Figure 4 .

$$
\operatorname{TSR}(-)=\frac{\omega \mathrm{R}}{\mathrm{u}_{\mathrm{w}}}=\frac{\frac{2 \pi}{60} \times \mathrm{RPM} \times \mathrm{R}_{\text {rotor }}}{\mathrm{u}_{\mathrm{w}}}
$$

The summary of all equipment that was used for the wind tunnel experiments can be found in Table 1: 
Table 1. Wind tunnel experimental equipment and relevant descriptions.

\begin{tabular}{|c|c|}
\hline Equipment & Description \\
\hline \multirow{3}{*}{ Wind tunnel facility } & Open jet Facility (TU Delft) \\
\hline & Wind speed ranges $0-30 \mathrm{~m} / \mathrm{s}$ \\
\hline & Jet diameter $2.85 \mathrm{~m}$. \\
\hline \multirow{3}{*}{ Turbine generator(s) } & Both are 3 phase PMSG \\
\hline & $\mathrm{P}_{\text {rated }}=375 \mathrm{~W}$ \\
\hline & 3 bladed upwind $(\mathrm{R}=0.87 \mathrm{~m})$ \\
\hline \multirow{3}{*}{ Rotors used } & 5 bladed upwind $(\mathrm{R}=0.86 \mathrm{~m})$ \\
\hline & 5 bladed upwind large $(\mathrm{R}=1.06 \mathrm{~m})$ \\
\hline & 3 bladed downwind $(\mathrm{R}=0.85 \mathrm{~m})$ \\
\hline \multirow{3}{*}{ Grid-tied inverters } & DF-SUN500-GWAL \\
\hline & Custom-made for WindChallenge \\
\hline & 3 phase bridge rectifier Zhejiang Jing Tai \\
\hline \multirow[t]{2}{*}{ DC bridge rectifier } & Electronics \\
\hline & (MDS60-16) \\
\hline \multirow[t]{2}{*}{ DC controllable load } & KIKUSUI (PLZ1004 W) \\
\hline & DEWETRON (DEWE-5000) \\
\hline \multirow[t]{2}{*}{ Data loggers } & $\begin{array}{l}\text { National Instruments (cRio9063 with relevant } \\
\text { modules) }\end{array}$ \\
\hline & (before inverter) - DAQP-V-B module \\
\hline \multirow{4}{*}{ Voltage measurement } & (DEWETRON) with $0.05 \%$ accuracy \\
\hline & (after inverter) - DAQP-HV module \\
\hline & (DEWETRON) with $0.05 \%$ accuracy \\
\hline & Fluke i30 (current clamp) with Accuracy $<1 \%$ \\
\hline \multirow[t]{2}{*}{ Current measurement } & Chauvin Arnoux MN38 (current clamp) with \\
\hline & Accuracy $<1 \%$ \\
\hline
\end{tabular}

In Figure 5, a compilation of photos is presented showing all the experimental geometries tested in the jet of the OJF wind tunnel.
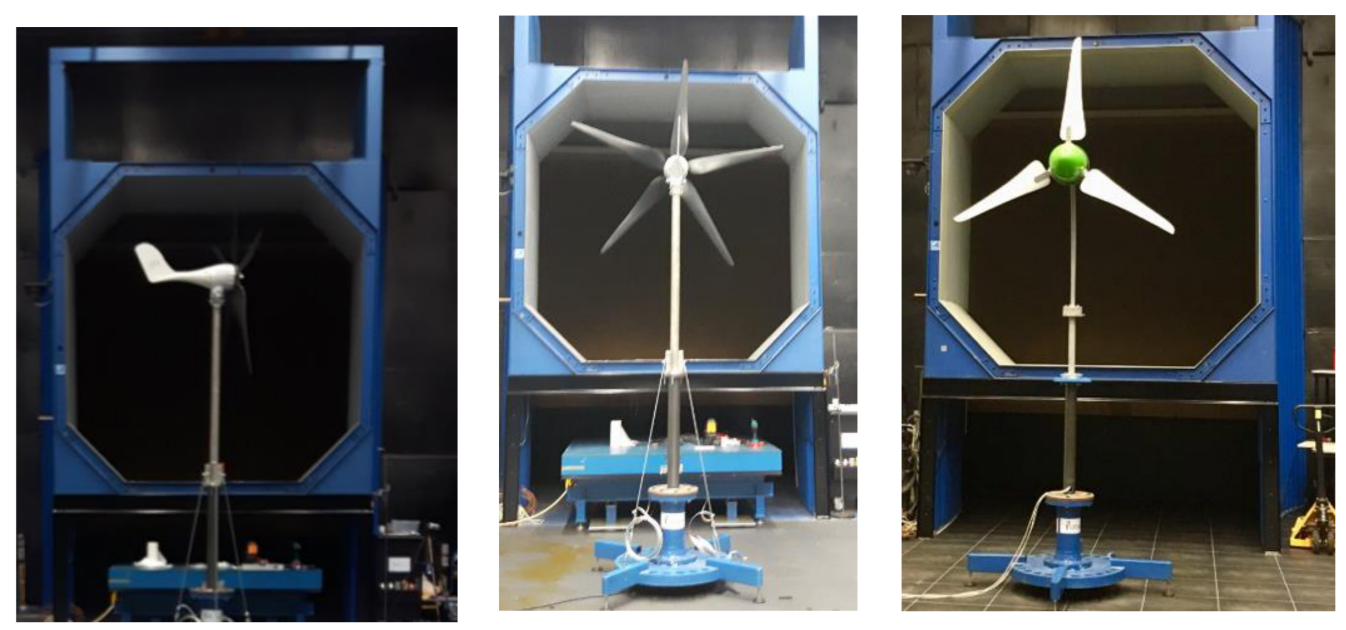

Figure 5. Photo-compilation of the micro wind turbines installed in front of the nozzle of the Open Jet Tunnel, (left photo) 5 bladed upwind in skewed flow configuration, (middle photo) 5 bladed upwind turbine in $0^{\circ}$ skew angle and (right photo) 3 bladed downwind turbine.

\subsection{Field Experiment}

Finally, field experiments were performed using the WindChallenge downwind micro wind turbine integrated on top of a noise barrier. The noise barrier was located at the road intersection of N470-A13 near TU Delft in the Netherlands. The micro wind turbine was situated on top of the noise barrier with the hub $2 \mathrm{~m}$ above the noise barrier. A special flange was fabricated in order to allow the micro wind turbine be attached on the noise barrier, as seen in the left part of Figure 6. The micro wind turbine was connected to its 
dedicated designed inverter and is grid connected similar to the sketch in Figure 3 . The power measurements, calculations, and equations were as explained in Figure 3. in the previous subsection. For the measurement of the hub's yaw direction, a digital compass was designed and integrated with the hub of the turbine as in Figure 1.

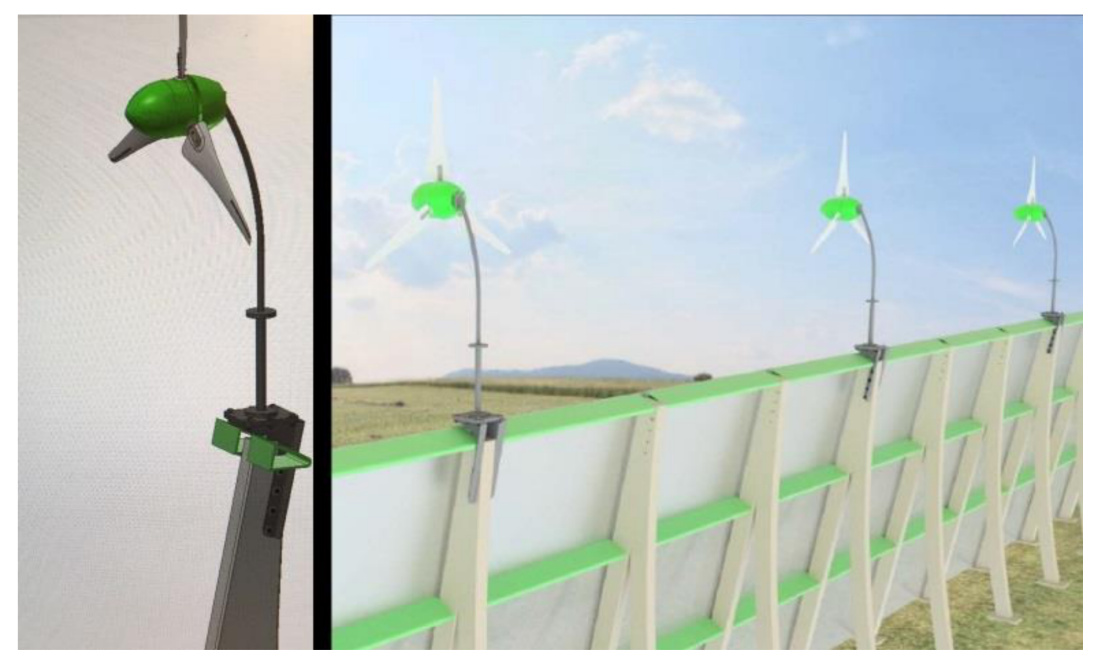

Figure 6. Visualization of the micro wind turbine structural integration with the noise barrier.

The observed directional data were then compared to the wind direction measured from the sonic anemometers next to the wind turbine as can be seen in Figure 7. The rotational speed of the micro wind turbine (RPM) was measured via a magnetic pulse counter installed on the hub's shaft. The RPM measured in combination with the local wind speed was used to define the tip speed ratio (TSR) of the micro wind turbine. The yaw orientation was also measured with the digital compass installed on the hub of the generator. Finally, the power was measured before and after the inverter similar to the wind tunnel set-up but with different data acquisition equipment and power, voltage, and current sensors of similar accuracy.

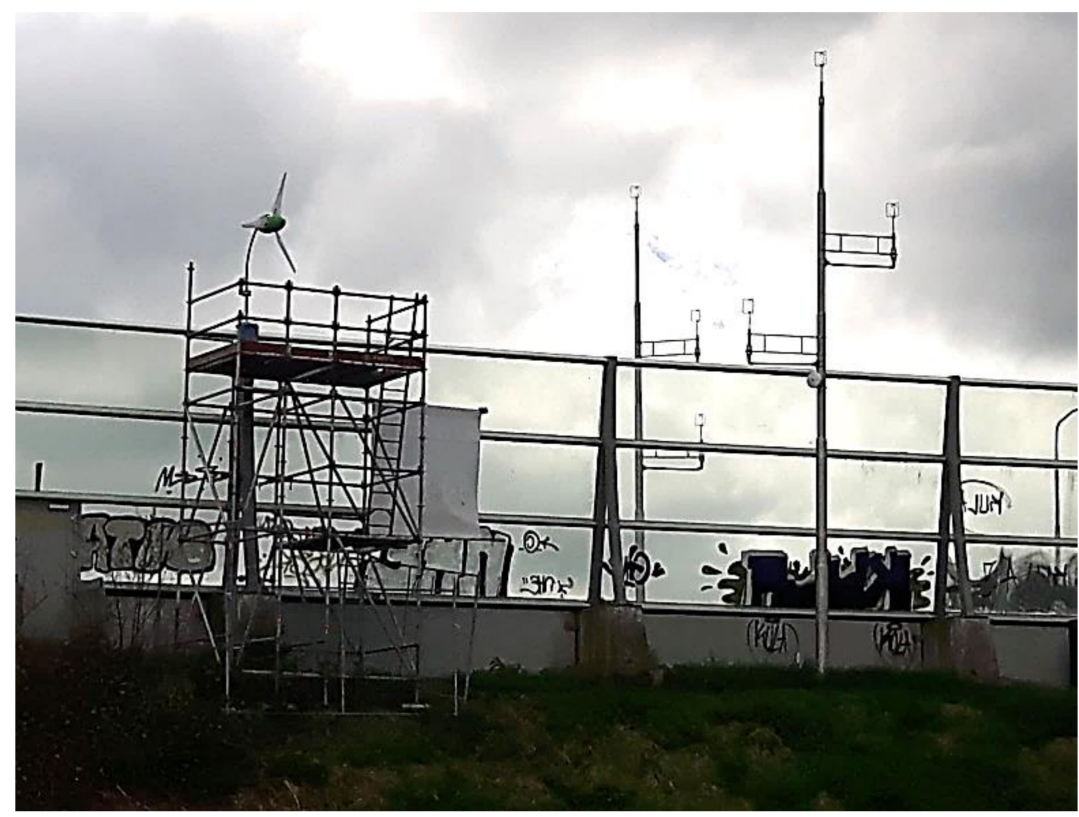

Figure 7. Micro wind turbine integrated on noise barrier field experiment. The 6 sonic anemometers are visible on the right located on two masts on three heights. The scaffolding behind the barrier is for access purposes and does not influence the incoming flow over the barrier. 
Finally, Table 2 below describes the equipment used.

Table 2. Field experimental equipment and relevant descriptions.

\begin{tabular}{ll}
\hline Equipment & Description \\
\hline Noise barrier & Height $=5.2 \mathrm{~m}$ \\
Wind turbine & 3 phase PMSG $-\mathrm{P}_{\text {rated }}=375 \mathrm{~W}$ \\
Rotor & 3 bladed downwind $(\mathrm{R}=0.85 \mathrm{~m})$ \\
Grid-tied inverters & WindChallenge \\
Current sensor (after inverter) & CR4200 (accuracy $+/-2 \%$ below 0.5 A and \\
& $+/-0.5 \%$ above it) \\
& EM24 DINAV53D1X \\
Current and voltage sensor (before inverter) & (Energy Meter before inverter with accuracy \\
& $+/-0.5 \%$ rdg \\
Data loggers & National Instruments (cRio9063 with relevant \\
& modules) \\
A magnetometer with that measures 0-360 \\
Digital compass & the orientation of the turbine. Sampling rate 15 \\
& Hz and stored at 10 Hz \\
RPM meter & Hall effect sensor with magnets placed inside \\
& the turbine's hub \\
\hline
\end{tabular}

\section{Results}

The following section includes the results relating to the performance characteristics addressed in the introduction with the experiments described in Section 2. Each subsection addresses each performance characteristic measured in the wind tunnel or the field test and relevant discussions address the importance with respect to the overall performance. The overall performance is addressed extensively with a post analysis in the Discussion section.

\subsection{Flow Misalignment Losses}

As presented in the Introduction, flow misalignment losses can play a detrimental role into the overall lifetime performance of the micro wind turbines. In this part, experimental results from wind tunnel tests of different rotors in different yaw angles are compared with the theoretical approaches. Finally, these theories are projected to potential losses due to inadequate yaw response of micro wind turbines on a noise barrier.

\subsubsection{Skewed Flow Losses}

The theories regarding skewed flow were compared with wind tunnel observations for different wind turbine configurations. Rotors were tested in different skewed flow angles with respect to the wind tunnel free stream. The difference of $\mathrm{P}_{\text {gen }}$ (watts) generated power before the inverter of 3 different rotors and the reference power $P_{\text {gen }}$ at a skew angle $\theta=0$ degrees is presented in Figure 8. The result is shown as the ratio $\eta_{y a w}(-)$ between the measured power and the reference power at zero skew angle:

$$
\eta_{\text {yaw }\left(\theta_{\mathrm{i}}\right)}(-)=\frac{P_{\text {gen }}\left(\theta_{\mathrm{i}}\right)}{P_{\text {gen }}\left(\theta=0^{\circ}\right)}
$$

The results for the DOD-Electric micro wind turbine in the 5 bladed and 3 bladed upwind rotor configurations are shown for yaw angles of $22^{\circ}$ and $45^{\circ}$ in Figure 8 . For angles of $22^{\circ}$, the difference was between $80 \%-95 \%$ of the reference power for all tested wind speeds. For 45 degrees, it dropped significantly to 35\%-65\% for the 5-bladed rotor and to $20 \%-35 \%$ for the 3 -bladed rotor. These differences might be attributed due to the blade aerodynamic performance and the controller. A decrease in the relative difference of power at higher wind speeds than $10 \mathrm{~m} / \mathrm{s}$ was observed. 

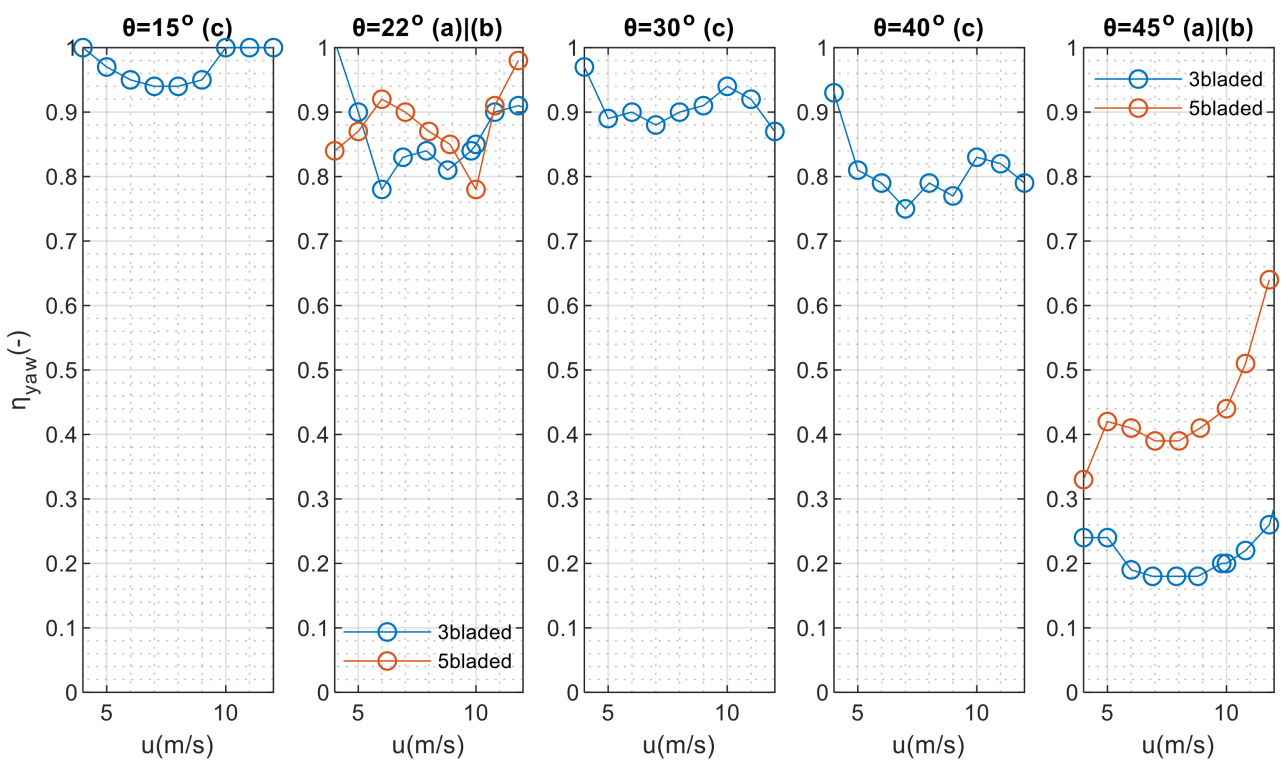

Figure 8. Ratio of experimentally measured power to the reference power at $\theta=0^{\circ}$ expressed as $\eta_{\text {yaw }}(-)$ at different skew angles $\theta\left(15^{\circ}, 22^{\circ}, 30^{\circ}, 40^{\circ}, 45^{\circ}\right)$ for (a) 5 bladed upwind, (b) 3 bladed downwind, and (c) 3 bladed downwind configurations.

For the 3-bladed downwind turbine, see in Figure 8, the different skew angles considered were $15^{\circ}, 30^{\circ}$, and $40^{\circ}$. There were no specific reasons for this difference with the other rotors. For $15^{\circ}$, the generated power was between $94 \%-100 \%$ of the reference power. For $30^{\circ}$ it drops to $85 \%-95 \%$ and for $40^{\circ}$ to $75 \%-85 \%$. This turbine seemed to have a better aerodynamic skewed flow performance than the other rotors, which could also be attributed to its controller and blade aerodynamic design.

Next, the theoretical approximations for yawed flow power were compared with the experimental data of the 3 different turbine configurations. The results are shown in Figure 9. The comparison was made with the $\cos \theta, \cos ^{2} \theta$, and $\cos ^{3} \theta$ theories, which were presented in the introduction of the article. Each theoretical generated power is presented in the equation below. These theories were coming mostly from rotor aerodynamics and thus do not include generator losses; however, the generator losses were assumed constant for any yaw angle $\theta\left(^{\circ}\right)$ to be compared. Thus $P_{\text {theoretical }}$ (watts) is estimated from the $P_{\text {gen }}$ (watts) power at the reference angle $\theta=0^{\circ}$.

$$
\begin{aligned}
& P_{\text {gen }}\left(\theta=0^{\circ}\right) \times \cos \theta_{\mathrm{i}} \\
\mathrm{P}_{\text {theoretical }}\left(\theta_{\mathrm{i}}\right)= & \mathrm{P}_{\text {gen }}\left(\theta=0^{\circ}\right) \times \cos ^{2} \theta_{\mathrm{i}} \quad \text { (watts) } \\
& \mathrm{P}_{\text {gen }}\left(\theta=0^{\circ}\right) \times \cos ^{3} \theta_{\mathrm{i}}
\end{aligned}
$$

To assess the validity of each theory using the experimental data, the following ratio $\eta_{\text {theory }}$ was used.

$$
\eta_{\text {theory }}=\frac{P_{\text {theoretical }}\left(\theta_{\mathrm{i}}\right)}{P_{\text {gen }}\left(\theta_{\mathrm{i}}\right)}
$$

For the $15^{\circ}$ yaw angle in Figure 9, the theoretical estimations were between $90 \%-105 \%$ of the experimentally recorded values for the 3 bladed downwind turbine. The $\cos \theta$ theory seemed to be the one closer to the reference value 1.

For the $22^{\circ}$ yaw angle in Figure 9, the theories give an approximation between $80 \%-$ $120 \%$ of the reference value for both upwind rotor configurations ( 3 bladed and 5 bladed). For both rotors the $\cos ^{2} \theta$ seemed to have better approximation. For different wind speeds, different approximations observed were probably attributed to the rotor aerodynamics and controller. 


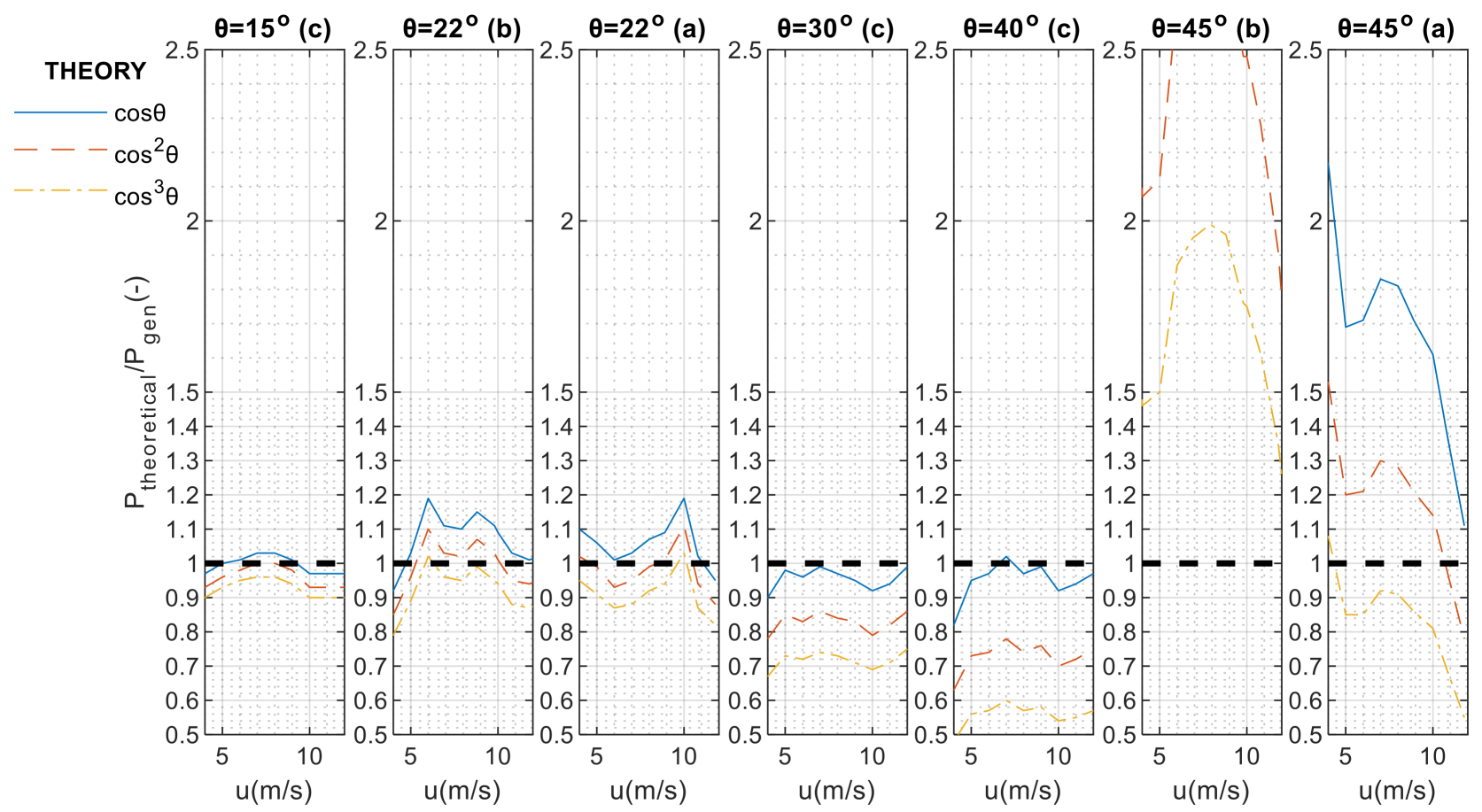

Figure 9. Ratio of theoretical power estimation from 3 different yaw misalignment theories at different skew angles $\theta^{\circ}\left(15^{\circ}\right.$, $22^{\circ}, 30^{\circ}, 40^{\circ}, 45^{\circ}$ ) with the experimentally derived generated power at these skew angles for (a) 5 bladed upwind, (b) 3 bladed downwind, and (c) 3 bladed downwind configurations.

For the $30^{\circ}$ yaw angle and the 3-bladed downwind rotor in Figure 9, the theories gave an approximation between $70 \%-98 \%$ of the reference value. All theories seem to underestimate the power generated from the rotor. The closest approximation was the $\cos \theta$ theory.

For the $45^{\circ}$ yaw angle and the 3-bladed and 5-bladed upwind rotor configurations in Figure 9, all theories seemed to fail dramatically in predicting the generated power. Especially for the 3 bladed rotor, all three theoretical models greatly over predicted the power production from values of $150 \%-200 \%$ for $\cos \theta$ up to $250 \%-300 \%$ for $\cos ^{2} \theta$. For the $\cos ^{3} \theta$ model, the overprediction was even out of the range doubling the value reaching $400 \%$. For the 5 -bladed configuration, the theories were somewhat between $60 \%-200 \%$ of the theoretical values. In high wind speeds, the $\cos ^{2} \theta$ and $\cos ^{3} \theta$ theories under predicted power and in lower wind speeds, where the $\cos \theta$ and $\cos ^{2} \theta$ theories are over predicting power. The $\cos ^{3} \theta$ theory seemed to be the most promising model. However, the large deviations in the results led us to conclude that all the cosine theories failed to predict greatly above 40 degrees skew angle.

Finally, it was also observed that the ratio between measured power and theoretical power for the skewed angle experiments varied with increasing wind speed. This can most probably be attributed to the non-optimal control strategies of the turbines.

At this point, the findings, highlights and conclusions with respect to the theories that predict the flow misalignment losses will be discussed below:

(1) It is evident from Figure 8 that when any rotor configuration was exposed to a misaligned flow, the power performance dropped. This drop of power production due to misalignment for micro wind turbines on top of noise barriers is of importance to assessing the overall performance.

(2) $\cos \theta, \cos ^{2} \theta$, and $\cos ^{3} \theta$ theories for skewed flow did not manage to accurately reproduce the measured wind turbine power performance in wind tunnel conditions for micro wind turbines for all wind speeds and yaw angles. The hypothesis was that aerodynamics of the various rotors plus the control scheme that each turbine 
had, influenced the power output of the wind turbine in this skewed conditions in a non-linear way resulting in large deviations.

(3) The $\cos \theta$ theory seemed to work quite well for the (c) configuration which was also the one that will be used in the field experiment. Thereby, this theory is used to estimate potential losses in the next sub-section.

(4) For all the other cases, both theories can lead to great deviations of the actual estimation of the power output. Thus, such theories must be treated carefully to accurately estimate wind energy yield on top of noise barrier, or any wind turbine installation point where flow was skewed by $15^{\circ}$ and more (e.g., rooftops) and if the wind turbine to be installed did not have its own custom-made inverter, or was intentionally designed for highly complex turbulent environments.

\subsubsection{Inadequate Yaw Response Losses}

The yaw response is the turbine's hub effort to align at any point of time with the wind direction. The wind turbine's hub was a free-moving mass on top of a bearing that should align with the wind flow in order to extract the wind energy available in the most efficient way. If the hub does not respond fast enough in these changes, then the wind turbine runs the risk of extracting less energy that it is able to. Downwind turbines have a weight displaced far from the center of rotation. The downwind position allowed them to align with the flow, but the displacement of the weight (and the spinning rotor) led to a large inertia that was slowing down the yaw tracking of the rotor. In this study observations were made in order to approximate the losses due to this configuration. The effect was clearly demonstrated in the 2 minute example dataset shown in Figure 10. The dataset was sampled with $10 \mathrm{~Hz}$ for the wind speed, hub's yaw angle, and wind direction. It was clear that there was a mismatch between the alignment of the turbine's head with the upcoming wind direction, which gets larger in lower wind speeds. Nearly all the time it was shown that the turbine's hub was not aligned with the incoming flow.
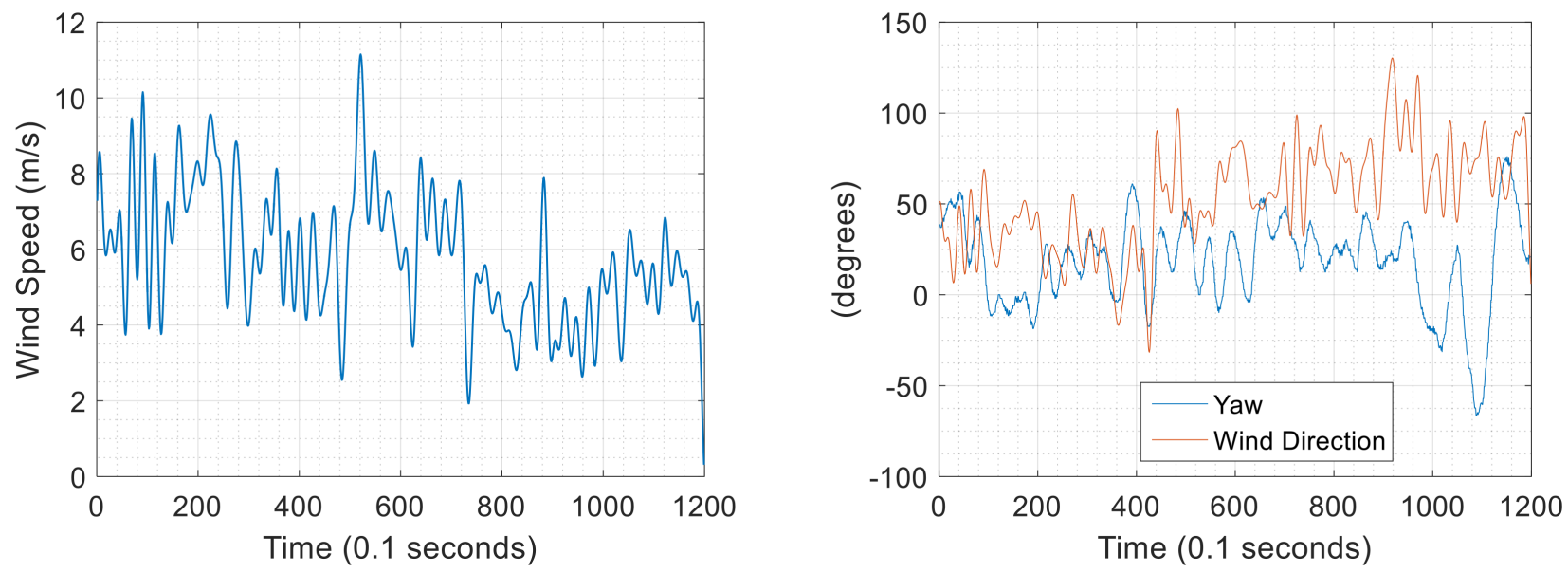

Figure 10. Data measured for a period of 2 minutes with $10 \mathrm{~Hz}$ sampling frequency, (left graph) Wind speed measured at hub height and 6 meters next to the micro wind turbine, (right graph) Yaw angle of the micro wind turbine and wind direction $\left(0^{\circ}\right.$ is North and $90^{\circ}$ is East) for WindChallenge turbine.

This yaw misalignment error was estimated for a dataset of 22 minutes with an average wind speed of $6.5 \mathrm{~m} / \mathrm{s}$. A duration curve of the mismatch of the flow and the yaw orientation is presented. This error was translated to a drop in power using the $\cos \theta$ theory. The average potential power performance decrease in all this dataset due to inadequate yaw response was $-37 \%$. The average recorded power performance coefficient $C_{p}$ of the turbine for this 22 minute dataset was 0.20 . If the turbine was able to follow the wind flow at all times, then the power performance would increase to an average of 0.273 rather than 0.20 , which is a substantial difference. From the power duration curve, in Figure 11 
(left graph), it can be seen that for about 500 seconds the misalignment was less than 30 degrees. This also means that over the remaining 820 seconds, so about $62 \%$ of time, the misalignment was large, which results in serious power losses. This calls for much more emphasis on dedicated yaw system designs for small urban wind turbines.
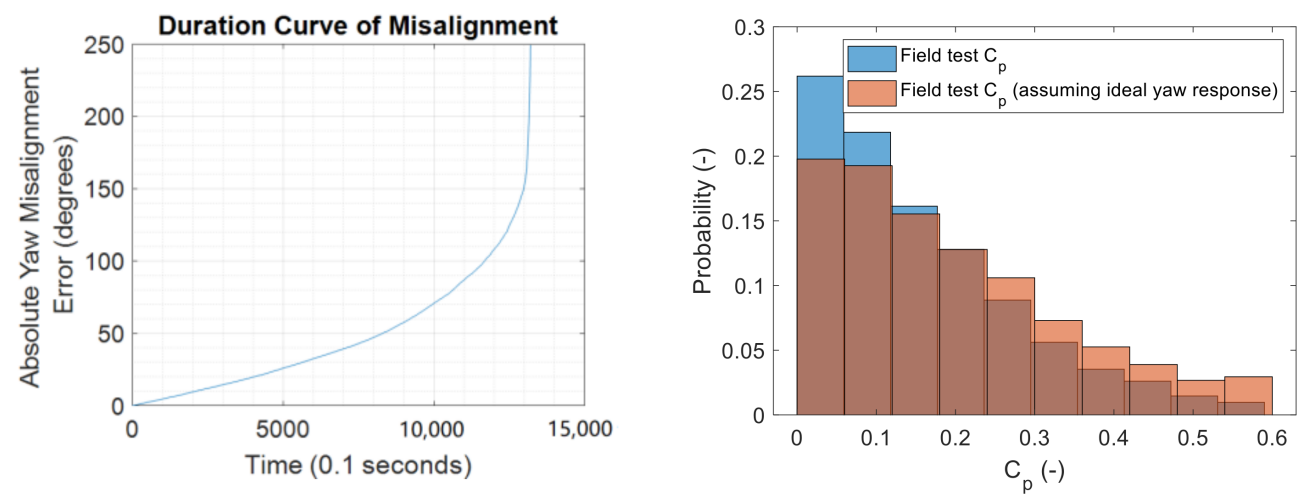

Figure 11. (left graph) Duration curve of the absolute yaw misalignment error (degrees), (right graph) histogram of probability of occurrence for $C_{p}$ values assuming ideal yaw response and comparison with actual measured from the $22 \mathrm{~min}$ dataset obtained in the field.

\subsection{Electrical System Losses}

The power available in the wind extracted by the micro wind turbine significantly reduced due to the aerodynamic performance of the rotor and the generator's losses, power drops as shown in Figure 12 when comparing the red with the green curve. Next, the inverter and control caused the power to drop further (blue curve).
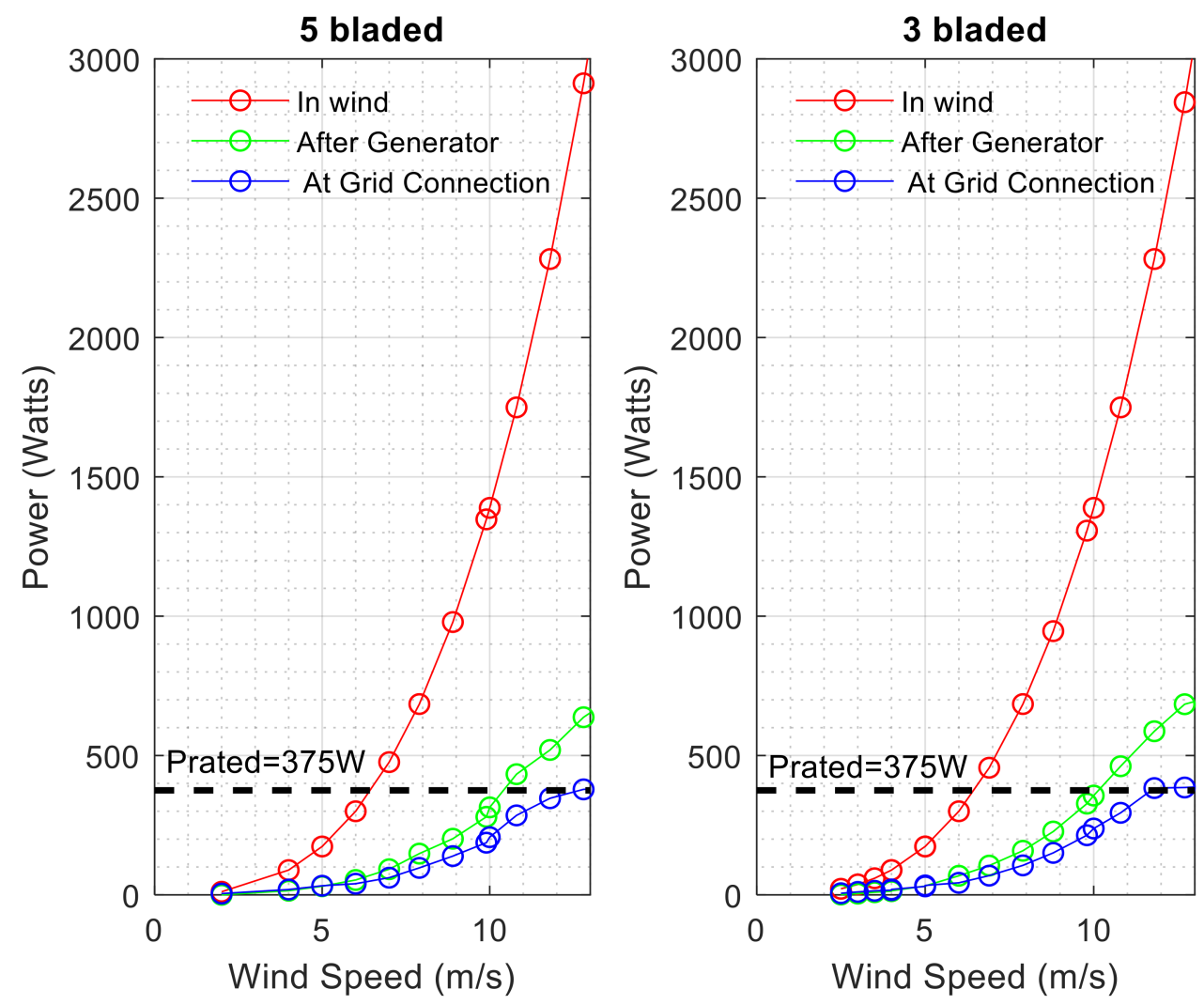

Figure 12. Available wind power (red), generated power (green), and delivered power to the grid (blue). 
Up to $10 \mathrm{~m} / \mathrm{s}$ the aerodynamic and generator losses dominated. In the region above $10 \mathrm{~m} / \mathrm{s}$, the inverter conversion losses started to increase, while at the same time, the loss in power was also due to aerodynamics (stall or pitch control) and/or the controller function to limit current from generator by means of electrical resistance.

During the experiments, the inverter efficiencies were recorded for the power conversion together with the standby power consumption losses. These were losses in order to keep the controller running, light indications, anti-islanding relays, and other isolation units.

These losses were divided into two main components:

(1) Inverter operating efficiency

(2) Standby power consumption losses

\subsubsection{Inverter Operating Efficiencies}

Inverter operating efficiency is crucial in order to convert the power in an efficient and reliable manner to bring to grid quality standards (for example 230 volts at $50 \mathrm{~Hz}$ frequency for Europe). The inverter efficiency was calculated from the ratio of $P_{\text {grid }}$ (watts) and $P_{\text {gen }}$ (watts). Results for 2 different inverters are shown in Figure 13.

$$
\eta_{\text {inverter }}(-)=\frac{P_{\text {grid }}}{P_{\text {gen }}}
$$

\section{3 bladed downwind (c)}

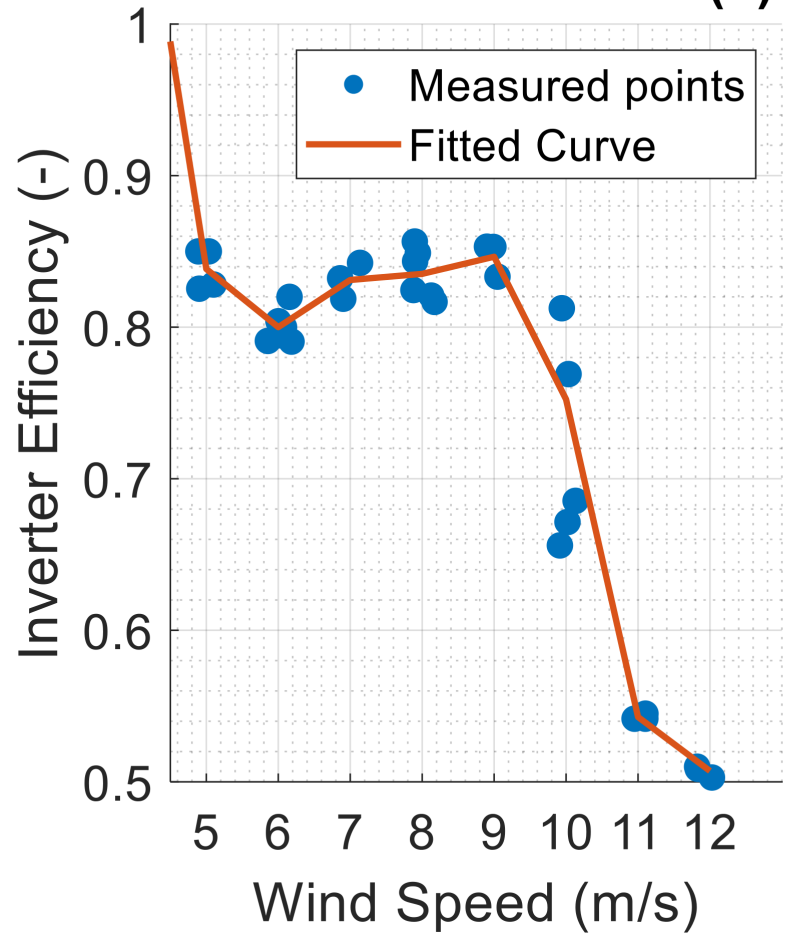

\section{3 bladed upwind (b)}

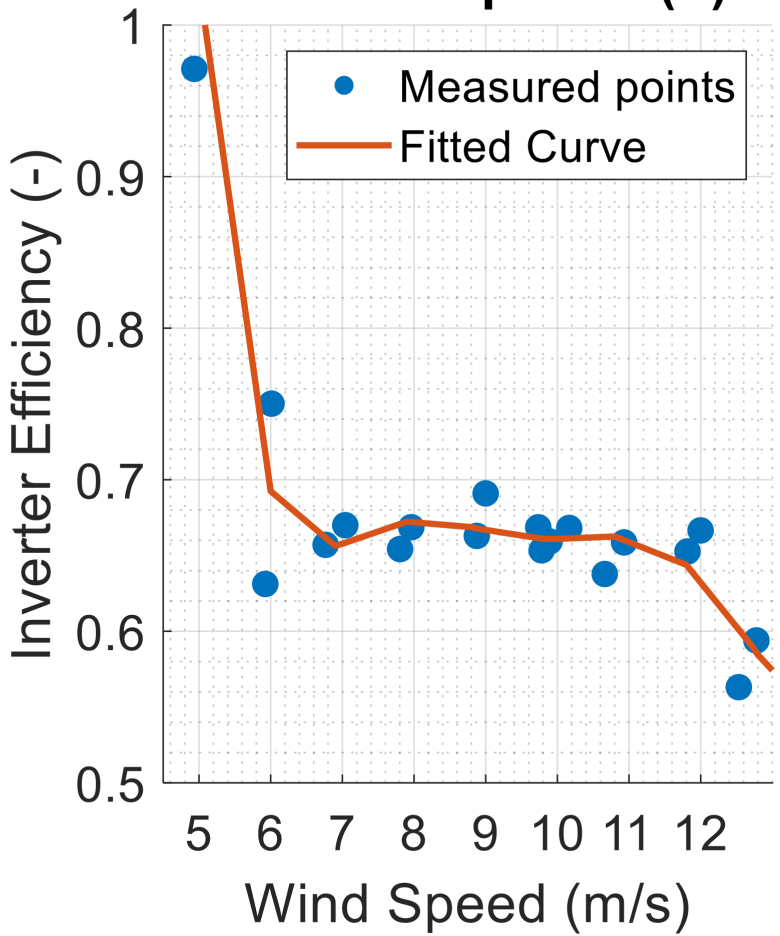

Figure 13. Wind tunnel measured inverter operating efficiencies as a function of wind speed for (left graph) the (c) configuration of 3-bladed downwind and (right graph) the (b) configuration of 3 bladed downwind configurations.

These losses should be part of the performance characteristics of a micro wind turbine project as they might greatly influence the final total annual energy yield that a potential micro wind turbine could deliver. The experiments indicated that a wind turbine with a PV MPPT inverter performs less than a micro wind turbine with a dedicated designed inverter. Finally, a note shall be made on the drop of performance after $10 \mathrm{~m} / \mathrm{s}$, which is an 
intentional measure of the control system in order to regulate the large increase in power and rotor over-speeding.

The inverter efficiency is shown in Figure 14 from the field experiment. It can be concluded that the inverter was performing as in the wind tunnel setting, by comparing with Figure 13 above with some deviations around the fitted line.
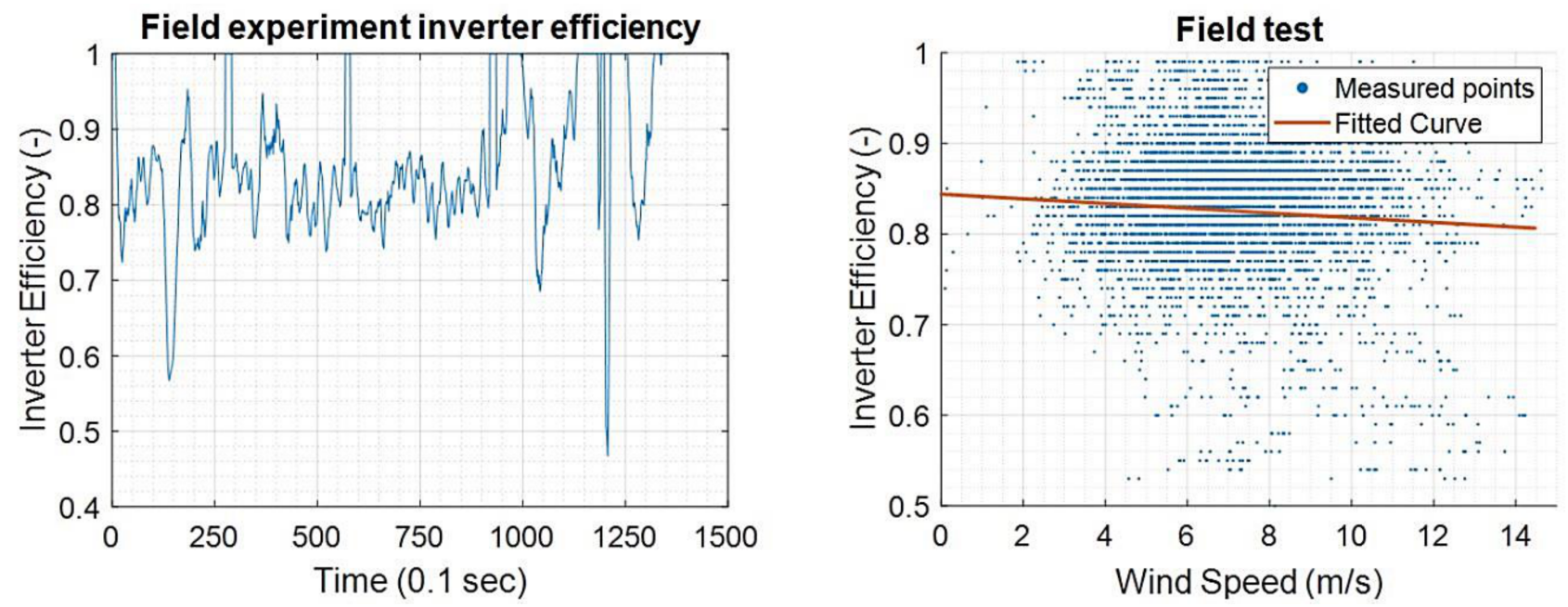

Figure 14. (left graph) Time series plot of a 2-min dataset (right graph) Scatter plot of field test for a 22 min dataset of measured inverter operating efficiencies for WindChallenge downwind turbine with average wind speed of $6 \mathrm{~m} / \mathrm{s}$.

\subsubsection{Standby Losses Assessment}

Another type of losses are standby losses. These typically reflect the electrical consumption of the inverter during standstill or idling conditions.

Measurements were made for different rotors and generators, for several inverters in the wind tunnel experiment and for one inverter for the field experiment. It was found that each inverter had an average constant loss during idling or full stop. The losses during idling of standby conditions were 2, 4, and 22 watts for (a), (b), and (c), respectively (see definition in Figure 9 for (a), (b), (c)).

The standby losses were used in annual energy calculations. For these annual yields, wind speed hourly datasets were used from the Royal Netherlands Meteorological Institute (KNMI) [38]. Several locations in the Netherlands were chosen (near coastal, inland etc.) as a production sensitivity parameter. All data from each station were evaluated on their validity and quality. Some datasets were neglected whenever there were Not a Number $(\mathrm{NaN})$ values, outliers, or other errors (due to weather station issues). The period of data acquisition assessed was from 01 January, 2018 until 31 December, 2019. The annual energy production estimations were made by interpolating the grid power output of the wind turbine's measured power curve with the query points of hourly wind speed for each location. This was a rough approach since at low wind speeds close to the standby loss point, typically, turbulence intensities are higher and might lead to a slight increase in instantaneous power output [39]. However, this increase was considered minimal in this experiment case since micro wind turbine were not able to follow all fluctuations in an instantaneous fashion without moving away from the optimal point of operation. The intention of this case study was to provide insight into how losses can increase when standby losses are taken into account or not.

Thereby, a power curve look-up table was used with the hourly wind speed $u_{t}(\mathrm{~m} / \mathrm{s})$ for each hourly time step $\mathrm{t}$ translated to an hourly energy output $\mathrm{E}(\mathrm{kWh})$. During the moments that power generation from the turbine was zero, the standby losses that were 
found in the wind tunnel experiments were subtracted. In that way, the influence of the standby losses on the Annual Energy Production AEP (kWh) was taken into account.

$$
\mathrm{E}\left(\mathrm{u}_{\mathrm{t}}\right)=\begin{aligned}
& -\mathrm{P}_{\text {standbyloss}}, \text { if }\left(\mathrm{P}\left(\mathrm{u}_{\mathrm{t}}\right)=0\right) \\
& \mathrm{P}\left(\mathrm{u}_{\mathrm{t}}\right)=\mathrm{P}\left(\mathrm{u}_{\mathrm{t}}\right), \text { if }\left(\mathrm{P}\left(\mathrm{u}_{\mathrm{t}}\right)>0\right)
\end{aligned}
$$

Once $\mathrm{E}\left(\mathrm{u}_{\mathrm{t}}\right)$ is defined for each time step, the annual energy production AEP $(\mathrm{kWh})$ is then the sum of each hourly time step.

$$
\operatorname{AEP}(\mathrm{kWh})=\sum_{\mathrm{t}=0}^{8760} \mathrm{E}\left(\mathrm{u}_{\mathrm{t}}\right)(\mathrm{kWh})
$$

The influence of standby losses on the total annual wind electricity production was presented for 3 locations in the Netherlands (De Bilt, Rotterdam, and IJmond) with mean wind speeds of $3.36,4.13$, and $6.97 \mathrm{~m} / \mathrm{s}$, respectively. For these calculations, the power curve of the downwind 3-bladed WindChallenge micro wind turbine was used, which was rated at 375 watts. A calculation was made for different inverter standby losses $(2,4$, and 22 watts) for fully aligned flow conditions. The first bar presented in Figure 15 below is the reference generated power excluding the standby losses. For low wind speed sites $(3.3 \mathrm{~m} / \mathrm{s})$, the standby losses were of a considerable amount $(5 \%, 10 \%$, and $50 \%)$. When average wind speed increased, the losses dropped significantly. The amount of standby loss also played a role.
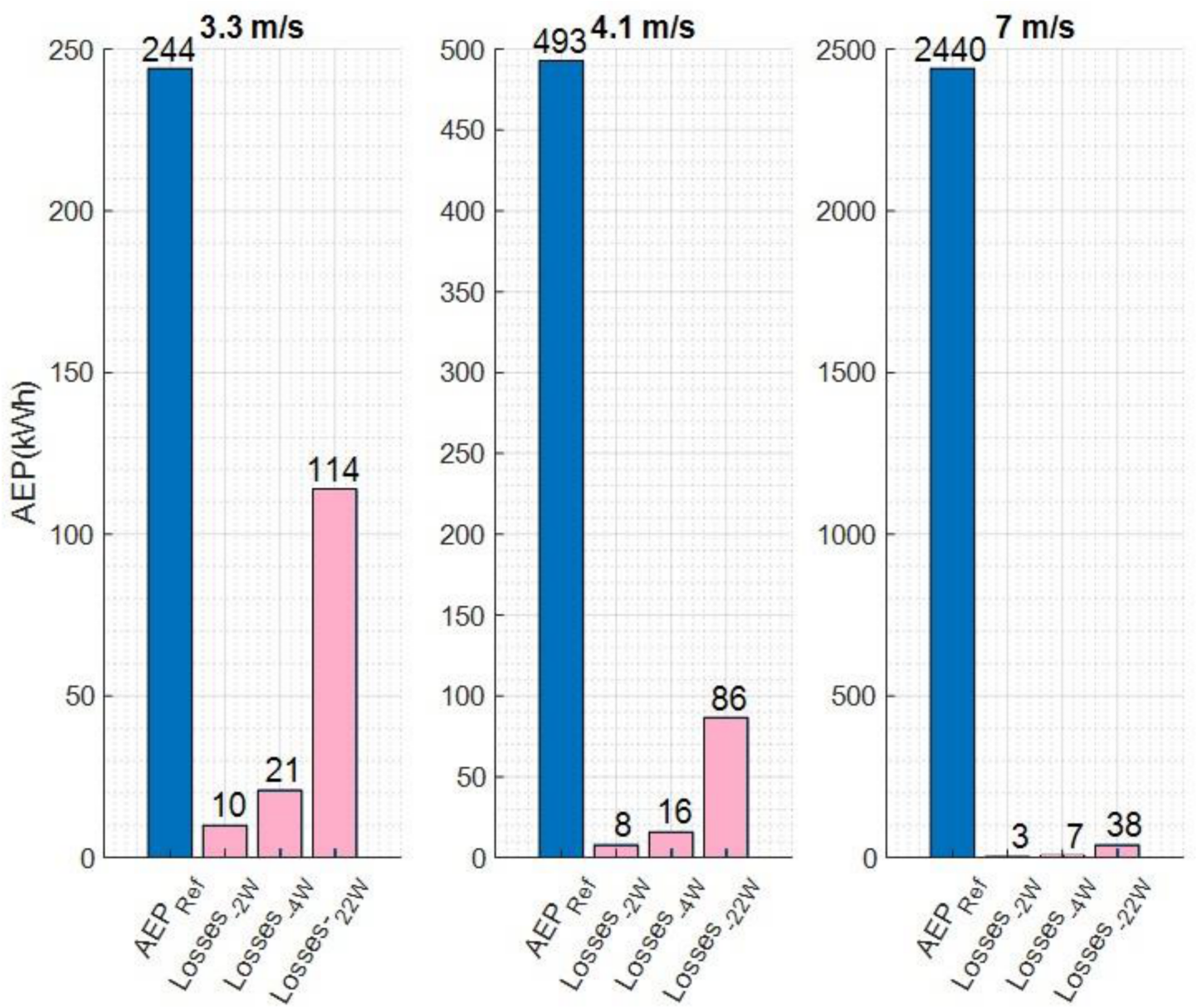

Figure 15. Annual Energy Production (AEP) for 3 sites with different annual mean wind speed $(\mathbf{l e f t}=3.3 \mathrm{~m} / \mathrm{s}$, middle $=4.1 \mathrm{~m} / \mathrm{s}$, right $=7 \mathrm{~m} / \mathrm{s})$ assessing the losses for 3 different inverter standby losses $(2,4$, and $22 \mathrm{~W})$ compared to the reference AEP. 


\subsubsection{Site Assessment Feasibility with Electrical Losses and Skewed Flow}

A more detailed assessment was conducted for 9 sites in the Netherlands from inland to nearly coastal wind climate conditions with increasing mean wind speeds of $2.7-5 \mathrm{~m} / \mathrm{s}$, measured at 10 meters height, whose details are found in Table 3 below. This was relevant because micro wind turbines usually are installed at such heights and will experience these mean wind speeds. The site characteristics are presented in the table below. This assessment was a sensitivity analysis for the effect of yaw misalignment and inverter standby losses (assuming 6 watts). It was assumed that whenever the turbine was not producing any power, a consumption of standby loss was occurring. The site that was the nearest to the noise barrier location of the field test was R'dam (Rotterdam) measured in an open field at an airport. The noise barrier site was located 10 kilometers away from that measurement point. By extrapolating the results for the standby losses shown in Figure 15, about $24 \mathrm{kWh}$ of losses were expected from a $493 \mathrm{kWh}$ reference AEP. This was a $\sim 5 \%$ decrease in AEP due to the standby losses.

Table 3. Wind Site characteristics including the Weibull lambda and k parameters that describe the wind regime for 9 locations.

\begin{tabular}{cccccccccc}
\hline Station & Arcen & De Bilt & Ell & Eindhoven & Maastricht & R'dam & Voorschoten & Schiphol & $\begin{array}{c}\text { R'dam } \\
\text { Geulhaven }\end{array}$ \\
\hline $\begin{array}{c}\mathrm{U}_{\text {mean }} \\
(\mathrm{m} / \mathrm{s})\end{array}$ & 2.7 & 3.3 & 3.3 & 3.5 & 3.7 & 4.1 & 4.3 & 4.7 & 5 \\
$\lambda(\mathrm{scale})$ & 3.02 & 3.79 & 3.71 & 4.02 & 4.20 & 4.64 & 4.83 & 5.41 & 5.68 \\
$\mathrm{k}(\mathrm{shape})$ & 1.60 & 1.96 & 1.66 & 1.84 & 1.98 & 1.82 & 1.81 & 1.96 & 2.23 \\
\hline
\end{tabular}

The results for the assessment of the 9 sites are presented in the curves in Figure 16. In particular the annual energy production is plotted versus the increasing wind speed per site, The conclusions derived are:

(1) Energy yield was higher for higher mean wind speeds.

(2) The annual energy production (AEP) standby losses were lower at higher mean wind speed as the wind turbine produces more time and stays less time inactive, consuming standby power.

Figure 17 shows the ratio of AEP (kWh) with and without the standby losses. It was clear how much overestimation of predicted power can occur especially in the low wind speed regions. Another important finding was that there are cases where the combination of low site average wind speed, large average yaw angle that the rotor is exposed, and a specific rotor could lead to even a net consumer wind turbine system rather than producing one overall a year. This was seen well for the 3 bladed upwind turbine in the left graph and for yaw angles of $45^{\circ}$.

It was also clear that some wind rotors have much more beneficial production, such as 3-bladed downwind, which is due to better aerodynamic performance in yawed flow, better controllers, and possibly lower grid connection wind speed leading to less losses. 

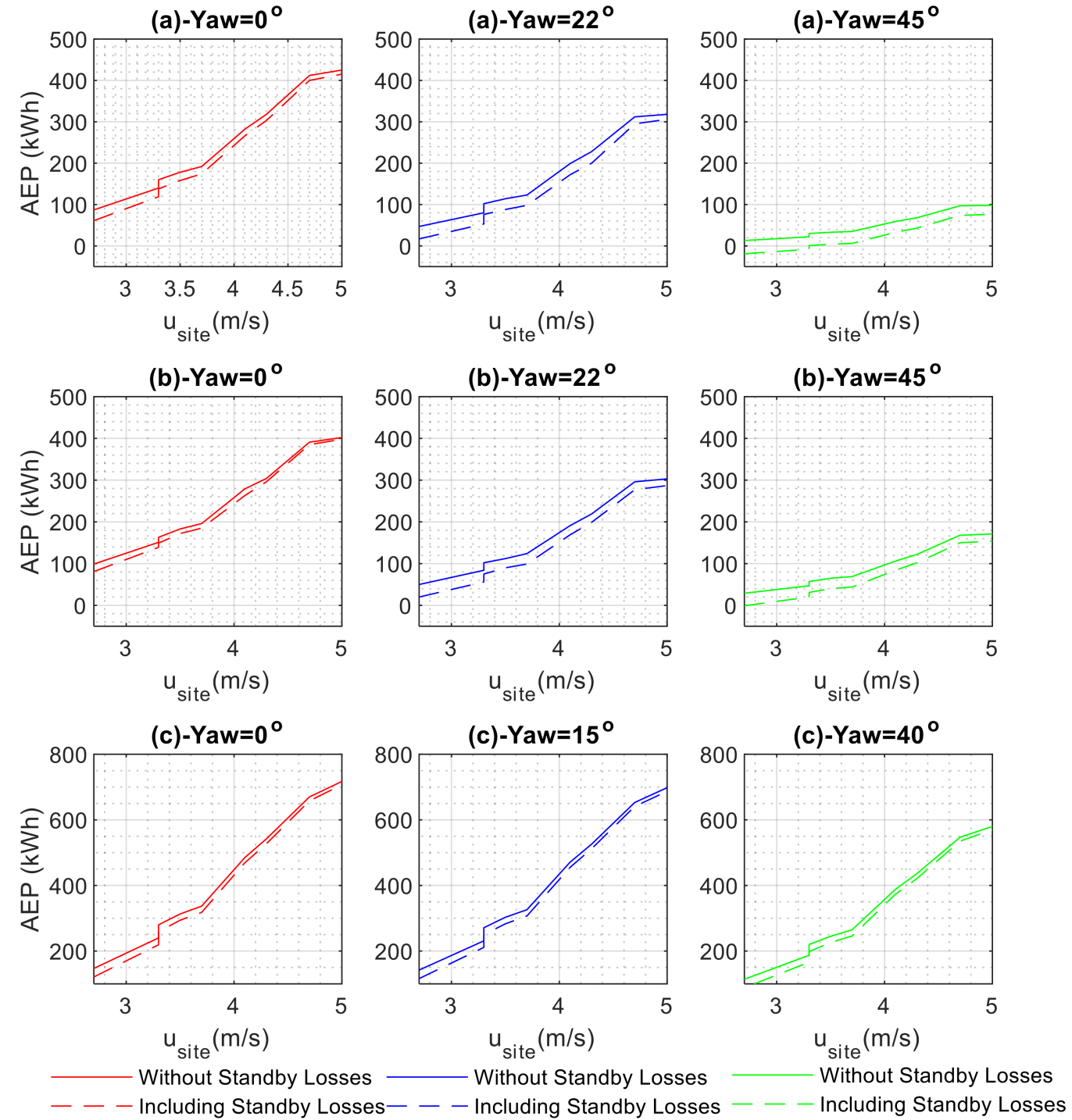

Figure 16. Annual Energy Production AEP (kWh) without and including standby losses for an increasing mean wind speed per different site and different yaw angles for (a) 5 bladed upwind, (b) 3 bladed downwind, and (c) 3 bladed downwind configurations.
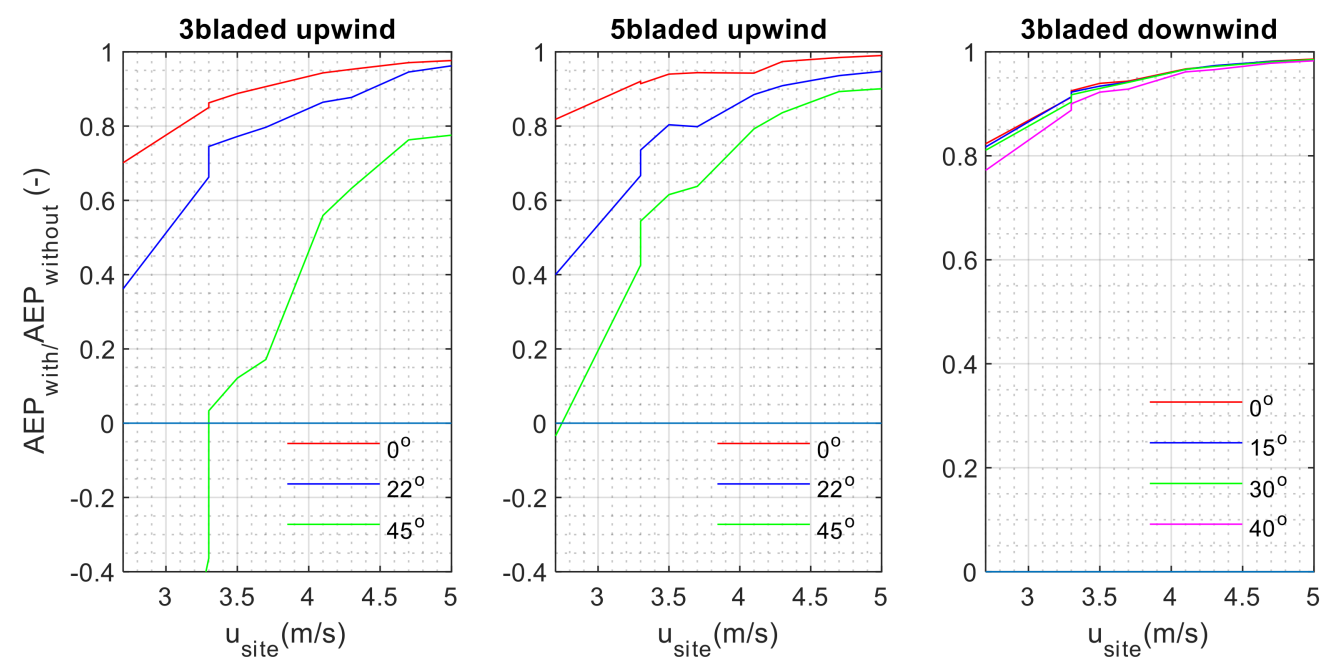

Figure 17. Ratio of Annual Energy Production with and without the standby losses plotted for increasing mean wind speed $\mathrm{u}_{\text {site }}(\mathrm{m} / \mathrm{s})$ per different site and different yaw angles $\theta\left(^{\circ}\right)$. 


\subsection{Optimal Power Control Performance}

Micro wind turbines have an aerodynamic maximum operating point at which they harvest maximum power from the available wind power. However, when placed in the field there are a number of factors that might lead to deviations from those optimal points. These factors have to do with the micro wind turbine design, the turbulent nature of wind speed at low heights, and the control system of the wind turbine. Observations from a wind tunnel experiment are presented showing the best operating point and the corresponded tip speed ratios and performance coefficients for micro wind turbines and then are compared with real-field measurements in order to give an impression of the micro wind turbine's behavior on the field and identify the room for improving the performance characteristics of micro wind turbines.

\subsubsection{Cp and Tip Speed Ratio Measurements in a Wind Tunnel}

A test was performed by using the DC load set-up where the RPM of the generator could be controlled through voltage and thus the maximum aerodynamic power coefficient of this particular rotor was found. Figure 18 below presents the results for 2 rotor configurations with 5 blades (a smaller and a larger rotor diameter). For both rotor diameters it was found that the maximum performance was between a tip speed ratio (TSR) of 4-6. Also, as wind speed increased, the optimum $C_{P}$ was found in higher Tip Speed Ratios (TSR). Also, the $C_{P}$ slightly decreased with increasing wind speeds. The $C_{p}$ was based on the ratio of aerodynamic power $P_{\text {aero }}$ (watts) and $P_{\text {gen }}$ (watts). $P_{\text {aero }}$ (watts) was based on the air density $\rho_{\text {air }}\left(\mathrm{kg} / \mathrm{m}^{3}\right)$, rotor radius $R_{\text {turbine }}(\mathrm{m})$ and wind speed $\mathrm{u}_{\mathrm{w}}(\mathrm{m} / \mathrm{s})$.

$$
\begin{gathered}
C_{p}=\frac{P_{\text {gen }}(\text { Watts })}{P_{\text {aero }}(\text { Watts })}(-) \\
P_{\text {aero }}=0.5 \rho_{\text {air }} \pi R_{\text {turbine }}{ }^{2} u_{w}{ }^{3} \text { (Watts) }
\end{gathered}
$$
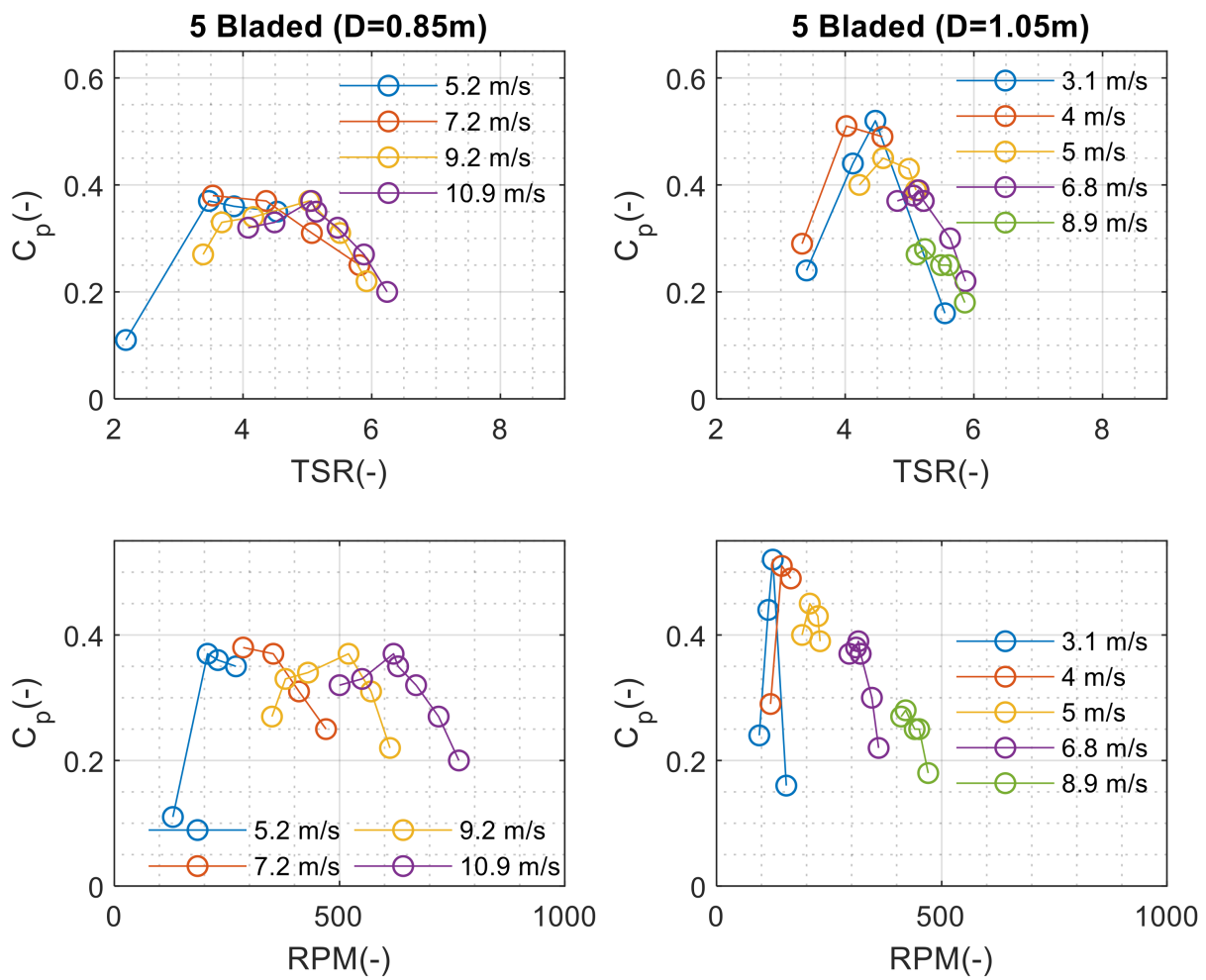

Figure 18. Wind tunnel results of generator's $C_{p}-\lambda$ (top) and $C_{p}-R P M$ (down) curves of different rotor diameter 5 bladed upwind rotor configurations (left graphs for $0.85 \mathrm{~m}$ diameter and right graphs for $1.05 \mathrm{~m}$ diameter) based on $\mathrm{P}_{\text {gen }}(\mathrm{W})$ power after the generator for different wind speeds (see legend). 
For the 3-bladed downwind micro wind turbine used in the field experiment, unfortunately a detailed $C_{p}-\lambda$ assessment was unfortunately not available. But data were extracted from the power curve characterization test including the RPM of the generator, thus the optimal operating point of the wind turbine for each wind could be found. The $C_{p}$ and TSR characteristic data for all wind speeds are presented below in Table 4 . This shows the power performance of the micro wind turbine for ascending wind speeds.

Table 4. $\mathrm{C}_{\mathrm{P}}$-TSR characteristic curve for the 3-bladed downwind turbine configuration derived from wind tunnel test.

\begin{tabular}{cccc}
\hline $\begin{array}{c}\text { Wind } \\
\text { Speed }(\mathbf{m} / \mathbf{s})\end{array}$ & RPM & $\mathbf{C}_{\mathbf{P}}$ & TSR \\
\hline 3.00 & 190.00 & 0.40 & 4.97 \\
4.00 & 240.00 & 0.40 & 4.71 \\
5.00 & 300.00 & 0.35 & 4.71 \\
6.00 & 360.00 & 0.34 & 4.71 \\
7.00 & 430.00 & 0.34 & 4.82 \\
8.00 & 490.00 & 0.30 & 4.81 \\
9.00 & 560.00 & 0.31 & 4.88 \\
10.00 & 690.00 & 0.29 & 5.42 \\
11.00 & 770.00 & 0.33 & 5.50 \\
12.00 & 880.00 & 0.30 & 5.76 \\
13.00 & 963.00 & 0.28 & 5.82 \\
\hline
\end{tabular}

\subsubsection{Performance of the Controller in the Field}

A 22-minute dataset was collected from the field experiment. An analysis was performed for the wind speed $U(\mathrm{~m} / \mathrm{s})$, Tip Speed Ratio (TSR), power performance $\left(\mathrm{C}_{\mathrm{p}}\right)$, and rotational speed (RPM), which were recorded with $10 \mathrm{~Hz}$ sampling frequency. By comparing the scatter plots in Figure 19 with the experimental results in Table 4, it was understood that there were significant mismatches with respect to the optimal performance measured in the controller wind tunnel conditions. In particular, by looking at the histogram of TSR, nearly $37 \%$ of time the TSR was between $2-4$, while $24 \%$ of time the TSR was between 4-6, which was the optimal range determined in the wind tunnel experiments. Looking at power performance coefficient consequently, a poor performance was also observed, with the turbine operating most of time not close to $30 \%-40 \%$ (as determined in the wind tunnel experiment).
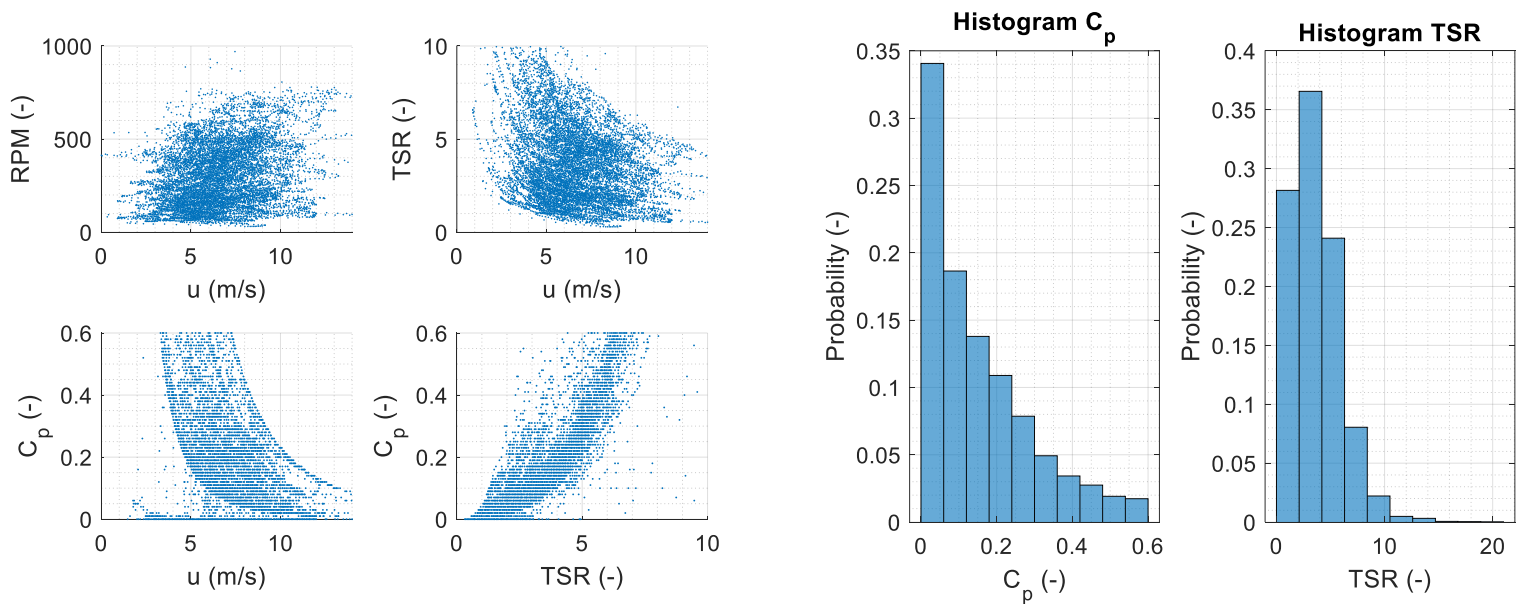

Figure 19. (left 4 graphs) scatter plots of the 22-minute dataset for wind speed $\mathrm{u}(\mathrm{m} / \mathrm{s})$, tip speed ratio, rotational speed (RPM), and coefficient of power performance $C_{p}$ (right 2 graphs) histogram of probability of occurrence for the power performance coefficient $c_{p}$ and tip speed ratio (TSR). 
This was also observed in the scatter plots where most data points co-exist for low TSR and low $C_{p}$ (bottom right scatter plot). The results were also assessed with a lower sampling frequency of $1 \mathrm{~Hz}$ (with resampling), which presented no deviations for TSR with mean values being 3.48 (at $10 \mathrm{~Hz}$ ) and 3.49 (at $1 \mathrm{~Hz}$ ). But for the result $\mathrm{C}_{\mathrm{P}}$, an overestimation of the value was found with $20.7 \%$ (at $10 \mathrm{~Hz}$ ) and $21.4 \%$ (at $1 \mathrm{~Hz}$ ). Therefore, we can conclude that lower sampling rate overestimated power performance coefficients.

The results as such did not indicate a potential solution to this mismatch but rather addressed this issue. Control strategies differ per micro wind turbine manufacturer. It was understood that control systems were giving a flexibility on the micro wind turbine to operate in the near ground low wind speed and turbulent environment. Technically this is done by allowing the voltages to rise more, in order to keep the micro wind turbine spinning. At low wind speeds, manufacturers tend to let the micro wind turbines operate at a higher tip speed ratio (with the price of less efficiency) in order to avoid a full stop of the micro wind turbine, while in higher wind speeds, they allow the turbine to operate at lower tip speed ratio to allow better control. This is evidently shown in the top-right scatter plot of figure above. It is hard to classify in which conditions of the field experiment, the controller allowed on purpose to lower or higher tip speed ratios to find the optimal point of operation. But the dynamics of the controller response and ability to follow the turbulent nature of wind together with the inertial responses of the turbine could definitely be a next step into research.

\subsection{Starting Behaviour and Idling Fatigue}

This section presents the findings of the starting and idling behavior of the micro wind turbine from the wind tunnel and field experiment. The micro wind turbine behavior was classified according to the following states:

(1) Complete Stop

(2) Idling

a. Rotor comes to idling condition from complete stop

b. Rotor comes to idling from generation

(3) Generation

a. Coming from stop condition

b. Coming from idling condition

These states are further described below:

During the complete stop phase, if the hub's yaw angle is misaligned with respect to the flow then the flow acts as a force to align the hub to the flow. The force acting on the rotor should be enough to rotate the hub to the direction needed. Figure 20 below shows results for different rotors tested in a wind tunnel from different yaw conditions. A 5 bladed and 3 bladed rotor with similar aerodynamic properties was exposed to an incremental wind speed increase in the wind tunnel starting from $90^{\circ}$ yaw misalignment until the point the rotor started aligning fully with the flow (refer to the left image in Figure 5). It is clear that the 5 bladed rotor with higher solidity needs higher wind speed to start the flow alignment. Also, another finding was that while the tail-vane of the micro wind turbine assisted the rotor to start rotating from the perpendicular misaligned position in lower wind speeds, it took slightly higher wind speeds for the rotor to align with the flow (observe the region between $2-3 \mathrm{~m} / \mathrm{s}$ ).

Once the alignment is successful, then the rotation of the turbine starts leading to either idling state or generating state, described below. 


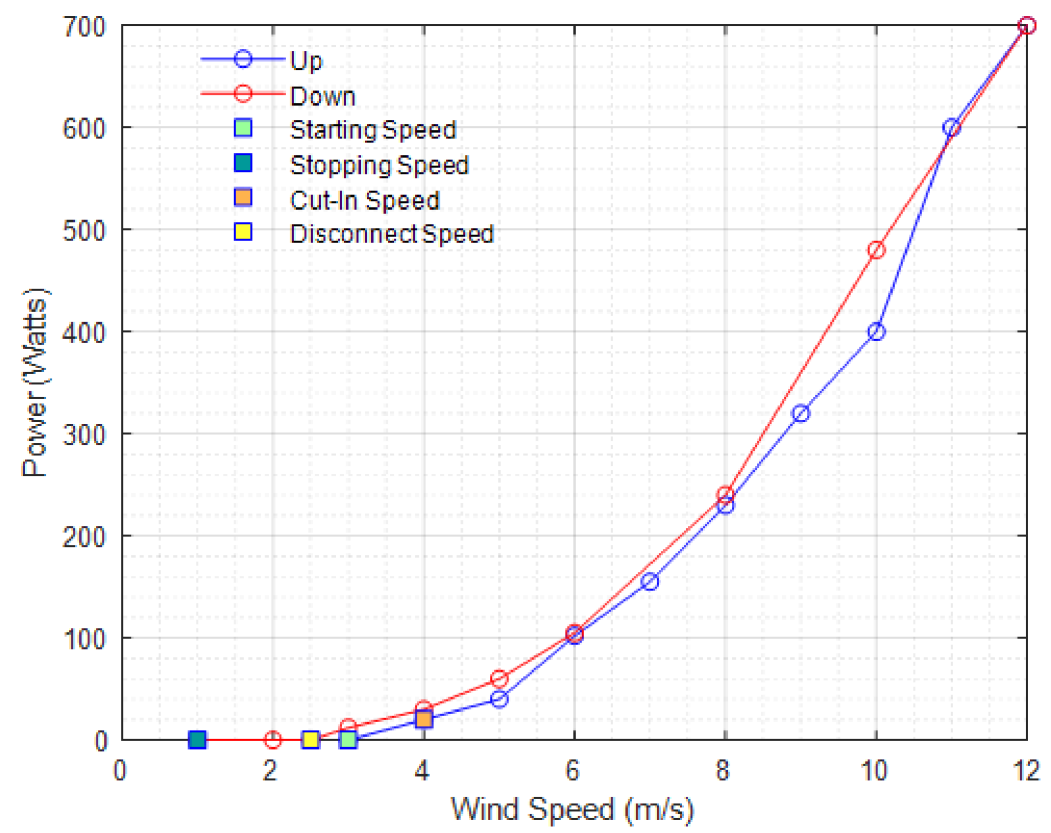

Figure 20. Experiment where rotor alignment with the flow is assessed from a complete stop and a $90^{\circ}$ misalignment and by increasing the wind speed until the rotor becomes fully aligned at $0^{\circ}$.

While idling, the rotor does not produce any power but is in a standby mode where the controller boosts the voltage to connect to the grid by, for example allowing higher rotational speed to generate sufficient inertia in the system and then boosting voltage to connect to the grid side. This mode can happen from either a complete stop of the rotor or a rotating turbine that generates power. These two possibilities are explained below:

During the point where the rotor comes to idling condition from complete stop, the rotor is aligned with the incoming flow and the aerodynamical power is enough to allow the rotor to spin up to a point that it has overcome the cogging torque of the generator. However, there's not sufficient voltage boost to connect to the grid. The wind speed resource and its turbulence characteristics in combination with the power do not allow for sufficient rotational speed to be built up and thus voltage to connect to the grid. A final remark on this state, is that a combination of low wind speed with high turbulence and some small magnitude gusts are needed to bring the rotor to this condition.

In the stage when the rotor comes to idling from generation, the turbine was connected to the grid and generating while the wind speed dropped significantly. Therefore, there was still inertia in the rotor, thus allowing for it to rotate up to a point that the voltage is not sufficient for grid interconnection. However, the aerodynamic wind speed power is enough to allow rotational movement by overcoming the generator's cogging torque.

While in generation mode, the turbine's generator voltage is sufficiently high to connect to the grid and the power electronics assure that the turbine is connecting to the grid and delivering power with the appropriate grid quality (typically 220 volts and $50 \mathrm{~Hz}$ ). The turbine can reach this state either from a period where the rotor was at full stop or a period where the wind regime was such to allow the turbine only to idle. These are described below:

In the stage of coming from stop condition, the rotor reaches rotational speed that is sufficient to build the sufficient voltage in order to connect to the local grid conditions from a complete stop. Current is now flowing effectively and the power electronics make their work to deliver power to the grid. A combination of a previous stage of complete stop due to low wind speeds and a sudden increase in wind speed with gust behavior might have allowed for this. 
The stage of coming from idling condition, is similar to the previous step, but the rotor is already rotating, thus it is easier for it to connect to the grid with a slight increase to the mean wind speed.

This behavior is quantified with a case study where the complete stop (State Zero), the idling mode (State One), and the generating mode (State Two) are assessed. This is quite important as during idling mode the wind turbine basically is not providing power while increase the overall cumulative fatigue to its components even though it is still in low rotational speeds. An algorithm was developed to assess this for 10-minute wind speed data for the place of Delft. The logic is quite simple and it considers 4 important wind speeds for the turbine, depicted from the explanations before. These are described below and presented in Figure 21 below:

(1) Starting Speed $u_{\text {start }}(\mathrm{m} / \mathrm{s})$, this happens when the rotor starts rotating and has to be monitored through the wind tunnel experiments.

(2) Stopping Speed $u_{\text {stop }}(\mathrm{m} / \mathrm{s})$, when rotor comes to a full stop.

(3) Cut-In Speed $u_{\text {cut-in }}(\mathrm{m} / \mathrm{s})$, when the generator connects to the main grid coming from a complete stop condition.

(4) Disconnecting Speed $u_{\text {dis }}(\mathrm{m} / \mathrm{s})$, for which the turbine was still rotating before but in an idling condition.

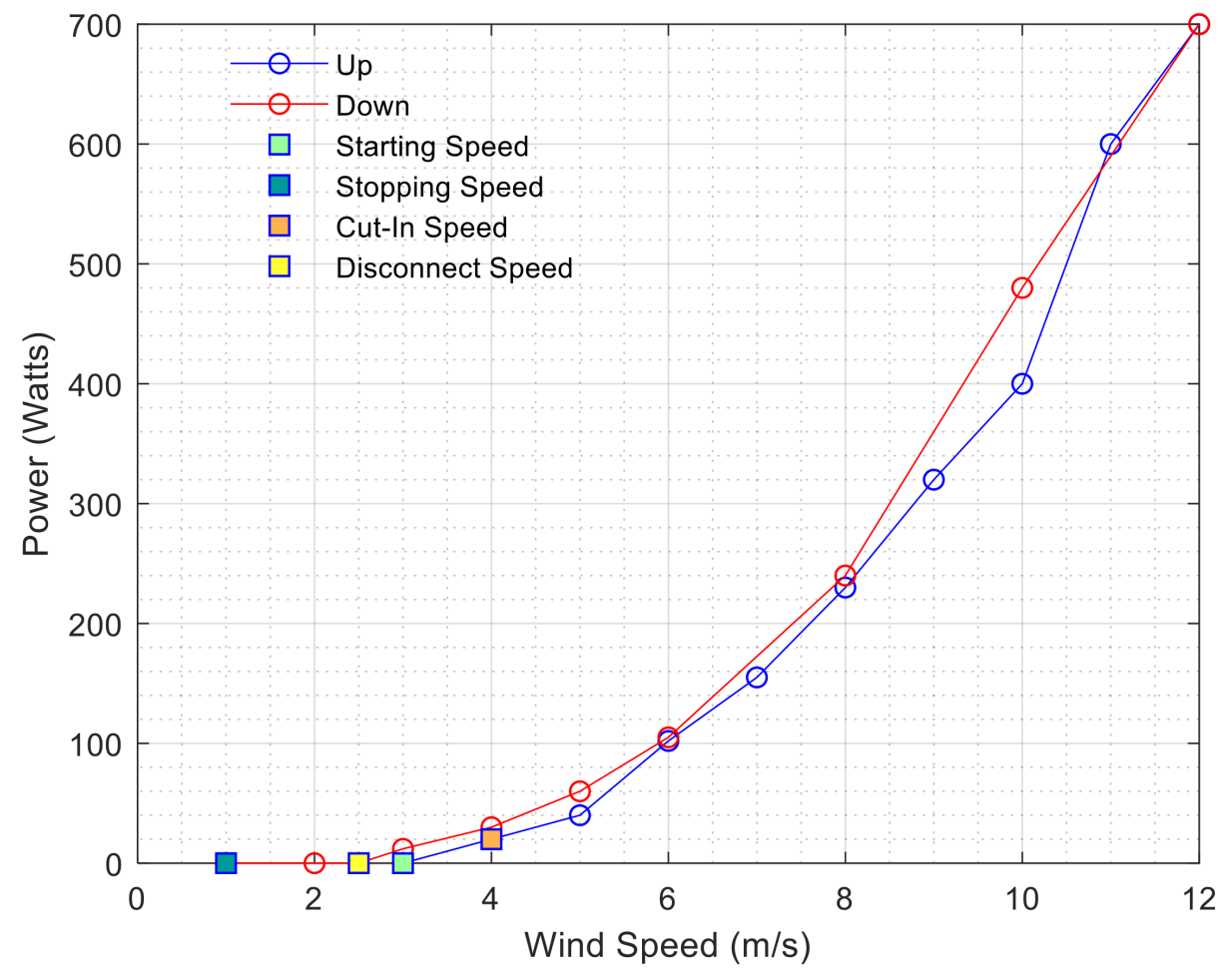

Figure 21. Power curve recordings with an increasing (up) wind speed and then decreasing (down) wind speed. Characterizing wind speeds are noted in the legend box.

Using an annual wind speed dataset from Rotterdam airport's weather station, the different wind turbine states were determined along the logic scheme plotted in Figure 22. Thus, the amount of time was quantified when the turbine was actually generating, idling, or being at a full stop. This happened by assessing the previous state of the turbine in each time step. The region between $2.5-4 \mathrm{~m} / \mathrm{s}$ is quite important as the turbine might come from either a generating point or a full stop point. The logic is described below. 


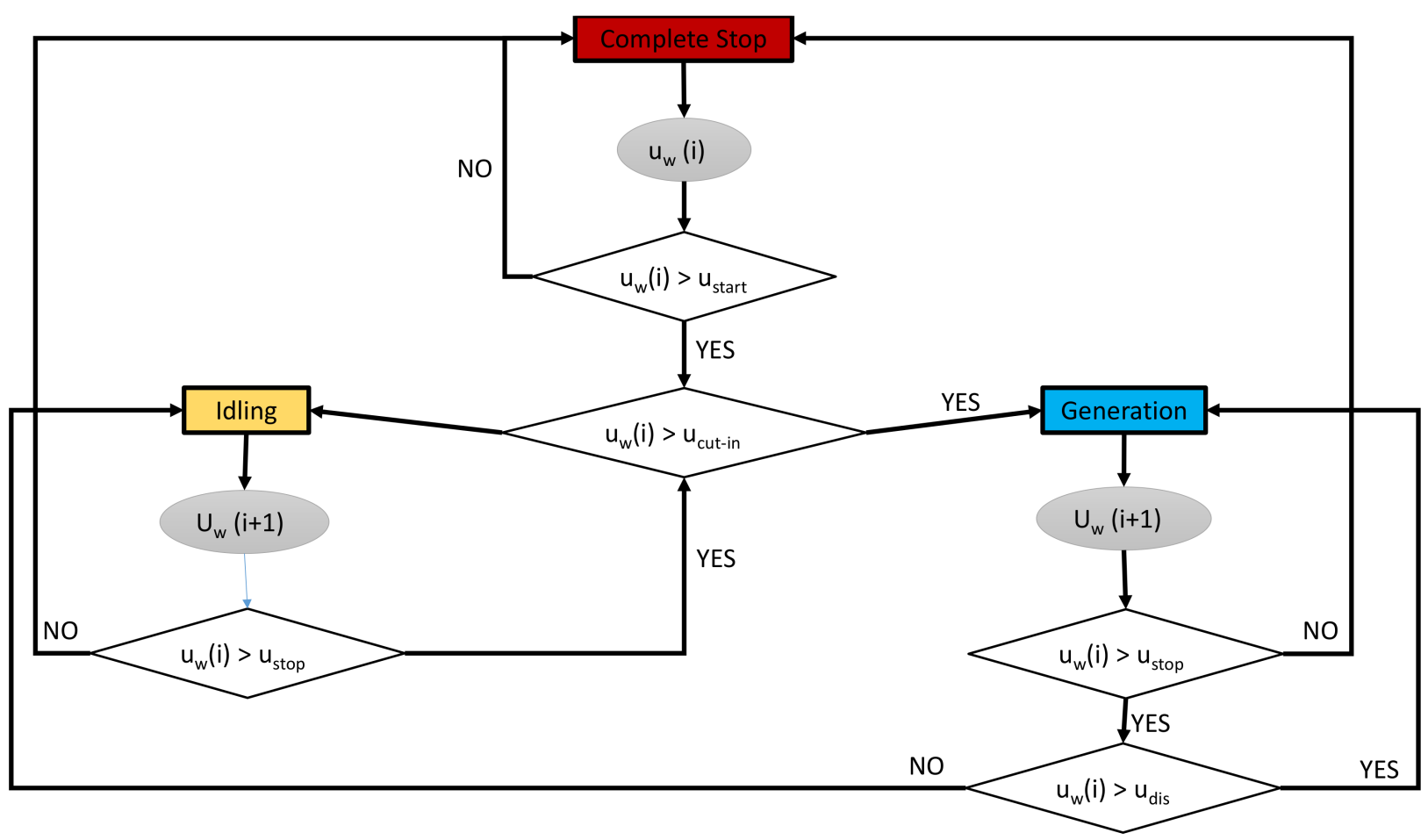

Figure 22. Flow diagram for idling state assessment.

The results from this case study are presented in Figure 23, where State One represents the idling stage for this particular site and accounts for $15 \%$ of time, while complete stop (State Zero) is for $22 \%$ of time and generation (State Two) is at $63 \%$ of time.
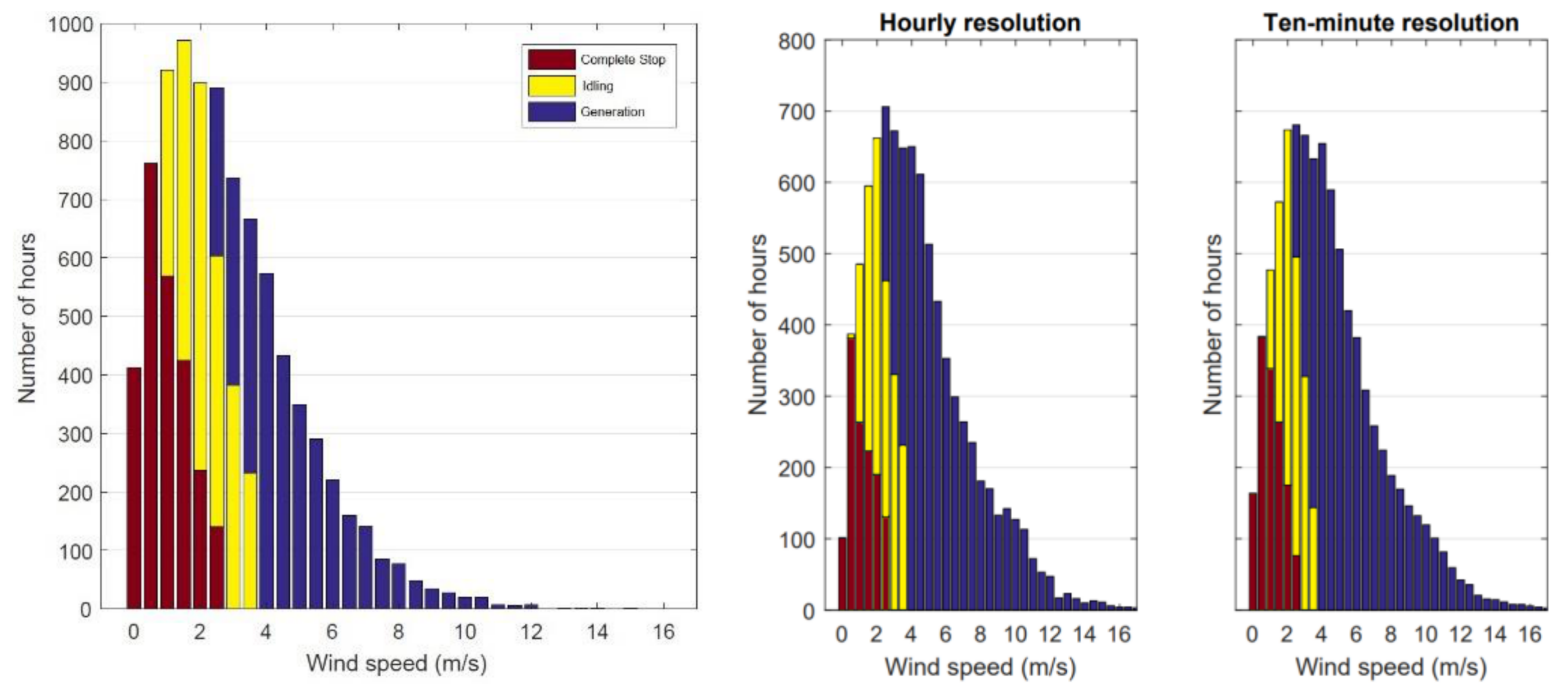

Figure 23. (left graph) Case study for different wind turbine states in legend: (State Zero) rotor at complete stop and turbine not generating, (State One) rotor is idling and not generating, and (State Two) rotor is rotating and generating. (middle and right graph) Different time resolutions.

Table 5 presents the distribution between stop, idling and generating for three different wind speed. When the mean wind speed of a site increases the idling states decreases and generation increase. For example, between 3 to $5 \mathrm{~m} / \mathrm{s}$ idling reduces from $29 \%$ to $22 \%$ while generation increase from $41 \%$ to $57 \%$. 
Table 5. Distribution of different wind turbine states for different sites mean wind speeds.

\begin{tabular}{cccc}
\hline Mean Wind Speed (m/s) & $\mathbf{3}$ & $\mathbf{4}$ & $\mathbf{5}$ \\
\hline State Zero (complete stop) & $30 \%$ & $23 \%$ & $21 \%$ \\
State One (idling) & $29 \%$ & $28 \%$ & $22 \%$ \\
State Two (generating) & $41 \%$ & $49 \%$ & $57 \%$ \\
\hline
\end{tabular}

\section{Discussion}

This experimental study, inspired by the large number of articles that examine the performance of micro wind turbines, has cross validated many of the claims for their different performance characteristics. From the theoretical and experimental research work on flow misalignment, to the electrical system losses with a great emphasis on the standby losses, which are typically neglected, and from the control system losses to the findings on turbine idling state. All these results are very relevant for the noise barrier application, but could very well be projected to any urban micro wind turbine system. The results indicate the necessity for micro wind turbine designers to redesign many of the subsystems in order to more efficiently capture the available urban wind energy. Finally, from an installer's point of view, the combination of the poor performance characteristics with the rather expensive cost of micro wind energy systems (compared to the more mature PV systems) and the particularly low wind speed regimes near ground, makes the techno-economical evaluation of a micro wind energy system challenging. All these uncertainties increase the financial risks for a profitable system installation. Another characteristic not addressed in this article is the maintenance demand of such a rotating electromechanical system, which could also affect the cost of electricity and it is proposed to be included in the future for further assessment.

To conclude this paper in a holistic way, a final post-analysis of the results was made to picture the overall performance of the micro wind turbine in the field presented in Table 6 . To understand where there could be points of improvement, the ideal power production was estimated by interpolating the wind speed measurements for the 22 minute dataset with the idealized wind tunnel measured power curve before the inverter. Then the ideal energy productions are summed for each timestep from the wind turbine. This was the base to estimate all the next ratios.

Table 6. Breakdown of ratio of energy measurements related to performance characteristics at field test with respect to the ideal performance in wind tunnel.

\begin{tabular}{cc}
\hline Energy Measurements (Production or Losses) & $\begin{array}{c}\text { Ratio of Energy Production or Losses with } \\
\text { the Ideal Performance in Wind Tunnel }\end{array}$ \\
\hline Net actual power production & $42 \%$ \\
Standby losses & $3 \%$ \\
Inverter losses & $5 \%$ \\
Losses from Inadequate Yaw Response & $18 \%$ \\
Controller performance losses (or other) & $33 \%$ \\
Ideal Power Production before inverter & $100 \%$ \\
(measured from wind tunnel) & \\
\hline
\end{tabular}

The measured actual power production data from the 22 minute dataset, right after the inverter and including standby losses, were summed and divided with the ideal production. It was found that the actual production was only $42 \%$ of the ideal one, which means that there were significant losses of $\sim 58 \%$.

These $58 \%$ losses were further classified into 3\% for the standby losses and $5 \%$ for the inverters power conversion losses. The next loss presented was due to the inadequate yaw response resulting in flow-rotor misalignment. This was estimated by multiplying in each time step the potential drop of power with the ideal power production before the inverter, then summing up and diving with the ideal one. It was found that $18 \%$ of these losses 
might be attributed to the inadequate yaw response. Finally, the remaining $33 \%$ of losses must be attributed to the poor controller performance and other losses.

The table presented above for the $22 \mathrm{~min}$ dataset for the average wind speed of $6.5 \mathrm{~m} / \mathrm{s}$ brings up a conclusion that there is still room for improvement for the micro wind turbines on noise barriers. Therefore, the installation of the examined wind turbine at the particular noise barrier is not yet a mature choice to be made.

\section{Conclusions}

In this section, the conclusions from the wind tunnel and field test of a micro wind turbine on noise barrier are summarized. The key conclusion is that the actual performance on the noise barrier in terms of energy yield was $42 \%$ from the ideal power production measured before the inverter in the wind tunnel. Eight percent of losses were due to the inverter and standby losses, $18 \%$ were due to inadequate yaw response to the wind flow, while the remaining $33 \%$ of losses were linked to poor controller performance. These results mean that there is still room to achieve the ideal performance as recorded in a controlled wind tunnel environment.

The key conclusions per performance category are summarized here. Flow Misalignment

(1) Power performance drops significantly with the increase of the flow skewed angle for which micro wind turbine's rotor is exposed on the noise barrier.

(2) $\cos \theta, \cos ^{2} \theta$, and $\cos ^{3} \theta$ decay laws do not accurately reproduce the actual power for different yaw angles and wind speeds.

(3) The micro wind turbine installed on top of the noise barrier presented a considerable flow misalignment for a 22 minute dataset (average wind speed of $6.5 \mathrm{~m} / \mathrm{s}$ ) resulting in an overall drop of $C_{p}$

Power conversion performance

(4) Inverter performance measured at the wind tunnel was fairly reproduced in the field experiment with small deviations.

(5) Standby losses from the inverter are not typically considered in Annual Energy Production estimations, but their importance should be addressed as in some case studies examined in this article, the combination of high standby losses and low wind speed regimes resulted in a net-consumer turbine.

Starting and idling of turbine

(6) The idling state of the micro wind turbine, which might result in increased fatigue without any useful generation, could occur between $20 \%-30 \%$ of a full year as it was assessed for sites with annual average wind speeds of three to five meters per second. Optimal Control

(7) Wind tunnel measurements of different rotors indicated that power performance coefficients were optimum for tip speed ratios between four to six for the tested turbines.

(8) These optimum points were achieved minimally in the field. A 20 min dataset post analysis indicated that $40 \%$ of time the TSR wqs between two to four, thus in an inefficient region, resulting in nearly $70 \%$ to operate at power performances below $20 \%$.

Author Contributions: Conceptualization, A.J.M.v.W. and G.J.W.v.B.; methodology, N.C.-A.; software, N.C.-A.; validation, (S.M.M.) and G.J.W.v.B.; formal analysis, N.C.-A.; investigation, N.C.-A.; resources, J.B. and N.C.-A.; data curation, N.C.-A. and J.B.; writing-original draft preparation, N.C.-A.; writing-review and editing, N.C.-A., G.J.W.v.B. and S.M.M.; visualization, N.C.-A.; supervision, G.J.W.v.B.; project administration, A.J.M.v.W. and G.J.W.v.B.; funding acquisition, G.J.W.v.B. and A.J.M.v.W. All authors have read and agreed to the published version of the manuscript. Please turn to the CRediT taxonomy for the term explanation. Authorship must be limited to those who have contributed substantially to the work reported.

Funding: This research was funded by STW, grant number 12728, under the acronym Duct4U. 
Institutional Review Board Statement: Not applicable.

Informed Consent Statement: Not applicable.

Acknowledgments: Many thanks to the support from TNO (Erik Slis), DEMO (Rajeev Bheemireddy), TU Delft Open JET Facility (Nico van Beek), Alliander for providing the micro wind turbines (especially J.B.), WindChallenge people (Sander Mertens).

Conflicts of Interest: The authors declare no conflict of interest.

\section{References}

1. Orrell, E.P. Benchmarking U.S. Small Wind Costs; PNNL: Richland, WA, USA, 2017.

2. Ran Fu, D.F.; Margolis, R.; Woodhouse, M.; Ardan, K.U. Solar Photovoltaic System Cost Benchmark: Q1 2017; National Renewable Energy Laboratory (NREL): Golden, CO, USA, 2017.

3. Encraft. Warwick Wind Trials Report; Encraft: Delhi, India, 2009.

4. CarbonTrustUK. Small-Scale Wind Energy_Policy Insights and Practical Guidance; The Carbon Trust: London, UK, 2008.

5. Udell, D.; Infield, D.; Watson, S. Low-cost mounting arrangements for building-integrated wind turbines. Wind. Energy 2010, 13, 657-669. [CrossRef]

6. Chrysochoidis-Antsos, N.; Amoros, A.V.; Van Bussel, G.J.; Mertens, S.M.; Van Wijk, A.J. Wind resource characteristics and energy yield for micro wind turbines integrated on noise barriers-An experimental study. J. Wind. Eng. Ind. Aerodyn. 2020, $203,104206$. [CrossRef]

7. Schreck, S.J.; Schepers, J.G. Unconventional Rotor Power Response to Yaw Error Variations. J. Phys. Conf. Ser. 2014, 555, 012001. [CrossRef]

8. Ciri, U.; Rotea, M.A.; Leonardi, S. Effect of the turbine scale on yaw control. Wind. Energy 2018, 21, 1395-1405. [CrossRef]

9. Bastankhah, M.; Porté-Agel, F. A wind-tunnel investigation of wind-turbine wakes in yawed conditions. J. Phys. Conf. Ser. 2015, 625, 625. [CrossRef]

10. Bastankhah, M.; Porté-Agel, F. Experimental and theoretical study of wind turbine wakes in yawed conditions. J. Fluid Mech. 2016, 806, 506-541. [CrossRef]

11. Qian, Y.; Zhang, Z.; Wang, T. Comparative Study of the Aerodynamic Performance of the New MEXICO Rotor under Yaw Conditions. Energies 2018, 11, 833. [CrossRef]

12. Pedersen, T.F. On wind turbine power performance measurements at inclined airflow. Wind. Energy 2004, 7, 163-176. [CrossRef]

13. Haans, W. Wind Turbine Aerodynamics in Yaw-Unravelling the Measured Rotor Wake; TU Delft: Delft, The Netherlands, 2011.

14. Tony, B.; David, S.; Nick, J.; Ervin, B. Wind Energy Handbook; John Wiley and Sons Ltd.: Hoboken, NJ, USA, 2001.

15. Bastankhah, M.; Porté-Agel, F. A New Miniature Wind Turbine for Wind Tunnel Experiments. Part II: Wake Structure and Flow Dynamics. Energies 2017, 10, 923. [CrossRef]

16. Hirahara, H.; Hossain, M.Z.; Kawahashi, M.; Nonomura, Y. Testing basic performance of a very small wind turbine designed for multi-purposes. Renew. Energy 2005, 30, 1279-1297. [CrossRef]

17. Verde, A.; Lastres, O.; Hernández, G.; Ibañez, G.; Verea, L.; Sebastian, P. A new method for characterization of small capacity wind turbines with permanent magnet synchronous generator: An experimental study. Heliyon 2018, 4, e00732. [CrossRef]

18. Chub, A.; Husev, O.; Blinov, A.; Vinnikov, D. Novel isolated power conditioning unit for micro wind turbine applications. IEEE Trans. Ind. Electron. 2017, 64, 5984-5993. [CrossRef]

19. Kristina, B.; Friedrich, W.F. Power Losses of Three Phase Rectifier topologies in smal wind turbines. In Proceedings of the PCIM Europe 2015, International Exhibition and Conference for Power Electronics, Intelligent Motion, Renewable Energy and Energy Management, Nuremberg, Germany, 19-20 May 2015.

20. Alvis, S.; Linards, G. Front-End Converter Choice Considerations for PMSG-based micro-wind turbines. In Proceedings of the 56th International Scientific Conference on Power and Electrical Engineering of Riga Technical University (RTUCON), Riga, Latvia, 14 October 2015.

21. Whaley, D.M. Low-Cost Small-Scale Wind Power Generation. Ph.D. Thesis, University of Adelaide, Adelaide, Australia, 2009.

22. James, P.; Bahaj, A.S.; Anwar, A.; Myers, L. Location, Location, Location: Domestic Small Scale Wind Field Report; Energy Saving Trust: London, UK, 2009; pp. 2-3.

23. Shawn, S.; Rowen, A.; Beavers, D.; Korn, D. Status Report on Small Wind Energy Projects Supported by the Massachusetts Renewable Energy Trust; The Cadmus Group Inc.: Waltham, MA, USA, 2008.

24. Ebert, P.; Wood, D. Observations of the starting behaviour of a small horizontalaxis wind turbine. Renew. Energy 1997, 12, 245-257. [CrossRef]

25. García-Gracia, M.; Romero, Á.J.; Ciudad, J.H.; Arroyo, S.M. Cogging Torque Reduction Based on a New Pre-Slot Technique for a Small Wind Generator. Energies 2018, 11, 3219. [CrossRef]

26. Bukala, J.; Damaziak, K.; Kroszczynski, K.; Krzeszowiec, M.; Malachowski, J. Investigation of parameters influencing the efficiency of small wind turbines. J. Wind. Eng. Ind. Aerodyn. 2015, 146, 29-38. [CrossRef] 
27. Martínez-Márquez, C.I.; Twizere-Bakunda, J.D.; Lundback-Mompó, D.; Orts-Grau, S.; Gimeno-Sales, F.J.; Seguí-Chilet, S. Small Wind Turbine Emulator Based on Lambda-Cp Curves Obtained under Real Operating Conditions. Energies 2019, $12,2456$. [CrossRef]

28. Loic, Q.; Clement, J.; Christian, E.C. Measuring the power curve of a small-scall wind turbine: A practical example. In Proceedings of the 1st International e-Conference on Energies, online, Switzerland, 14-31 March 2014.

29. Wegley, H.; Ramsdell, J.; Orgill, M.; Drake, R. Siting Handbook for Small Wind Energy Conversion Systems; Battelle Pacific Northwest Labs.: Richland, WA, USA, 1980.

30. ISO. ISO 16622-Meteorology—Sonic Anemometers/Thermometers-Acceptance Test Methods for Mean Wind Measurements; International Organization for Standardization: Geneva, Switzerland, 2002.

31. Predescu, M.; Bejinariu, A.; Nedelcu, A.; Mitroi, O.; Nae, C.; Pricop, M.V.; Craciunescu, A. Wind tunnel assessment of small direct drive wind turbines with permanent magnets synchronous generators. Renew. Energy Power Qual. J. 2008, 1, 306-311. [CrossRef]

32. Eltayesh, A.; Hanna, M.B.; Castellani, F.; Huzayyin, A.S.; El-Batsh, H.M.; Burlando, M.; Becchetti, M. Effect of Wind Tunnel Blockage on the Performance of a Horizontal Axis Wind Turbine with Different Blade Number. Energies 2019, 12, 1988. [CrossRef]

33. Chen, T.; Liou, L. Blockage corrections in wind tunnel tests of small horizontal-axis wind turbines. Exp. Therm. Fluid Sci. 2011, 35, 565-569. [CrossRef]

34. NATO. Wind Tunnel Wall Corrections; Ewald, B.F.R., Ed.; NATO: Brussels, Belgium, 1995.

35. Grant, I.; Mo, M.; Pan, X.; Parkin, P.; Powell, J.; Reinecke, H.; Shuang, K.; Coton, F.; Lee, D. An experimental and numerical study of the vortex filaments in the wake of an operational, horizontal-axis, wind turbine. J. Wind. Eng. Ind. Aerodyn. 2000, 85, 177-189. [CrossRef]

36. Sicot, C.; Devinant, P.; Loyer, S.; Hureau, J. Rotational and turbulence effects on a wind turbine blade. Investigation of the stall mechanisms. J. Wind. Eng. Ind. Aerodyn. 2008, 96, 1320-1331. [CrossRef]

37. Lignarolo, L.; Ragni, D.; Krishnaswami, C.; Chen, Q.; Ferreira, C.S.; Van Bussel, G. Experimental analysis of the wake of a horizontal-axis wind-turbine model. Renew. Energy 2014, 70, 31-46. [CrossRef]

38. KNMI. Uurgegevens Van Het Weer in Nederland-Hourly Data of Weather in the Netherlands. Available online: https: / / www.knmi.nl/nederland-nu/klimatologie/uurgegevens (accessed on 3 April 2019).

39. Kaiser, K.; Langreder, W.; Hohlen, H.; Højstrup, J. Turbulence Correction for Power Curves; Springer International Publishing: Berlin/Heidelberg, Germany, 2007; pp. 159-162. 